\title{
Reflective properties of melt ponds on sea ice
}

\author{
Aleksey Malinka ${ }^{1}$, Eleonora Zege ${ }^{1}$, Larysa Istomina ${ }^{2}$, Georg Heygster ${ }^{2}$, Gunnar Spreen $^{2}$, Donald Perovich ${ }^{3}$, and \\ Chris Polashenski ${ }^{4}$ \\ ${ }^{1}$ Institute of Physics, National Academy of Sciences of Belarus, 220072, pr. Nezavisimosti 68-2, Minsk, Belarus \\ ${ }^{2}$ Institute of Environmental Physics, University of Bremen, Otto-Hahn-Allee 1, 28359 Bremen, Germany \\ ${ }^{3}$ Thayer School of Engineering, Dartmouth College, Hanover, New Hampshire, USA \\ ${ }^{4}$ Cold Regions Research and Engineering Laboratory, Engineer Research and Development Center, Hanover, \\ New Hampshire, USA
}

Correspondence: Aleksey Malinka (aleksey.malinka@gmail.com)

Received: 25 July 2017 - Discussion started: 12 September 2017

Revised: 2 May 2018 - Accepted: 7 May 2018 - Published: 6 June 2018

\begin{abstract}
Melt ponds occupy a large part of the Arctic sea ice in summer and strongly affect the radiative budget of the atmosphere-ice-ocean system. In this study, the melt pond reflectance is considered in the framework of radiative transfer theory. The melt pond is modeled as a plane-parallel layer of pure water upon a layer of sea ice (the pond bottom). We consider pond reflection as comprising Fresnel reflection by the water surface and multiple reflections between the pond surface and its bottom, which is assumed to be Lambertian. In order to give a description of how to find the pond bottom albedo, we investigate the inherent optical properties of sea ice. Using the Wentzel-Kramers-Brillouin approximation approach to light scattering by non-spherical particles (brine inclusions) and Mie solution for spherical particles (air bubbles), we conclude that the transport scattering coefficient in sea ice is a spectrally independent value. Then, within the two-stream approximation of the radiative transfer theory, we show that the under-pond ice spectral albedo is determined by two independent scalar values: the transport scattering coefficient and ice layer thickness. Given the pond depth and bottom albedo values, the bidirectional reflectance factor (BRF) and albedo of a pond can be calculated with analytical formulas. Thus, the main reflective properties of the melt pond, including their spectral dependence, are determined by only three independent parameters: pond depth $z$, ice layer thickness $H$, and transport scattering coefficient of ice $\sigma_{\mathrm{t}}$.

The effects of the incident conditions and the atmosphere state are examined. It is clearly shown that atmospheric correction is necessary even for in situ measurements. The at-
\end{abstract}

mospheric correction procedure has been used in the model verification. The optical model developed is verified with data from in situ measurements made during three field campaigns performed on landfast and pack ice in the Arctic. The measured pond albedo spectra were fitted with the modeled spectra by varying the pond parameters $\left(z, H\right.$, and $\left.\sigma_{\mathrm{t}}\right)$. The coincidence of the measured and fitted spectra demonstrates good performance of the model: it is able to reproduce the albedo spectrum in the visible range with RMSD that does not exceed $1.5 \%$ for a wide variety of melt pond types observed in the Arctic.

\section{Introduction}

Melt ponds occupy a large fraction of the Arctic sea-ice surface in summer: up to $60 \%$ on multi-year ice according to Maykut et al. (1992) and up to $80 \%$ on landfast ice according to Langleben (1971) with more typical values between 20 and $40 \%$ (Polashenski et al., 2012; Rösel et al., 2012; Istomina 2015b). They reduce the ice albedo significantly and, therefore, increase the flux of absorbed sunlight energy and speed up the process of melting, thus amplifying the positive ice-albedo feedback effect (Curry et al., 1995; Eicken et al., 2004; Pirazzini, 2008; Schröder et al., 2014). Recent observations show that the melt onset is shifting earlier and the whole melt season is getting longer (Serreze et al., 2000; Dethloff et al., 2006; Perovich et al., 2008; Markus et al., 2009; Pistone et al., 2014). Moreover, as the prevailing sea-ice type has changed from multi-year ice to first- 
year ice in the recent decades (Comiso, 2012; Maslanik et al., 2007, 2011), the topography of the sea ice evolves from rough to uniform, flatter surface. As the melt pond fraction is closely connected to the relief of the sea ice (Polashenski et al., 2012), the maximum pond fraction is expected to increase as well. Therefore, including light reflection by melt ponds into climate models is an important task, particularly in light of the environmental changes observed recently (Flocco et al., 2010, 2012; Hunke et al., 2013; Lüpkes et al., 2013). A physical model of the reflective properties of melt ponds is needed for understanding the physics of sea ice, as well as for the correct interpretation of the results of remote sensing and field measurements (Herzfeld et al., 2006; Tschudi et al., 2008; Rösel et al., 2012; Zege et al., 2015).

The observed albedo of melt ponds varies over a wide range. They can change from light-blue ponds, when just formed, to dark mature ones, late in melt, meaning that the character of the ponds is important in addition to their coverage (Perovich, 1996; Barry, 1996; Nicolaus et al., 2010; Sankelo et al., 2010; Polashenski et al., 2012). Although there are quite a lot of measurements of melt pond spectral albedo (e.g., Perovich, 1994; Morassutti and Ledrew, 1996; Perovich et al., 2002, 2009), an adequate physical and optical model of melt pond reflection is still absent. Makshtas and Podgorny (1996) gave the analytical formula expressing the pond albedo in terms of the albedo of its bottom. However, despite asserting that bottom albedo is the main factor that determines the albedo of a pond as a whole, they did not address how to calculate it. This essential gap exists up to now. In this work we propose a simple solution for determining the pond bottom spectral albedo. This solution has required the detailed consideration of the inherent optical properties of sea ice, which forms the pond bottom. In addition, the question of the angular distribution of light reflected by a melt pond is still open. The angular distribution is highly important for understanding Arctic energy balance, because only the bidirectional reflectance is measured by satellite optical sensors and it is necessary to model the bidirectional reflectance distribution function (BRDF) to determine surface albedo from satellite data. Additionally, the processing of the reflectance measurement data, both satellite and ground-based, requires atmospheric correction, especially for polar regions. All these points are discussed in this work.

The paper is arranged as follows. First, our model of melt pond reflectance is described in Sect. 2. Section 2.1 presents the formulas for pond reflectance at various incident conditions. Inherent optical properties (IOPs) of sea ice are considered in Sect. 2.2. A simple analytical solution for bottom albedo in terms of the ice IOPs and its thickness is given in Sect. 2.3. Section 2.4 gives a final summary of the model developed. Section 3 discusses how illumination conditions are accounted for in processing and how the experimental results are interpreted. The atmospheric correction of experimental data is considered in Sect. 3.1. A possibility to use the near-IR reflectance as evidence of the ice grains' presence is discussed in Sect. 3.2. Notes about processing experimental data when the incident angle is unknown are given in Sect. 3.3. Then, Sect. 4 presents the verification of the developed model with the three datasets of in situ measurements (Polarstern-2012, Barrow-2008, and SHEBA-1998). The conclusion sums up the paper.

In this work we propose a simple optical model that enables the parameterization of the pond bottom albedo with a few physical characteristics and thus determines the spectral reflective properties of the melt pond as a whole, including its bidirectional reflectance.

\section{Model description}

\subsection{Radiance reflected by a melt pond}

We assume a pond to be a plane-parallel layer of melt water on an under-pond ice layer. Additionally we make the following assumptions:

1. the melt water is pure, with neither absorbing contaminants nor scatterers;

2. the Rayleigh scattering in water is negligible compared to the water absorption, so a ray inside the pond is attenuated according to the exponential law;

3. the pond bottom reflects light by the Lambert law (the reflected radiance is independent of the direction).

Makshtas and Podgorny (1996) give the following formula for the albedo of a pond that satisfies the abovementioned assumptions:

$A\left(\mu_{0}\right)=R^{\mathrm{F}}\left(\mu_{0}\right)+\frac{T^{\mathrm{F}}\left(\mu_{0}\right) \exp \left(-\varepsilon_{\mathrm{w}} z / \mu_{0}^{\mathrm{w}}\right) f_{\text {out }}\left(\varepsilon_{\mathrm{w}} z\right) A_{\mathrm{b}}}{n^{2}\left(1-A_{\mathrm{b}} f_{\text {in }}\left(\varepsilon_{\mathrm{w}} z\right)\right)}$,

where $R^{\mathrm{F}}\left(\mu_{0}\right)$ and $T^{\mathrm{F}}\left(\mu_{0}\right)$ are the Fresnel reflectance and transmittance of the water surface for incidence angle $\theta_{0}=$ $\arccos \mu_{0}, n$ is the refractive index of water, $\mu_{0}^{\mathrm{w}}$ is the cosine of the refractive angle, $z$ is the pond depth, $A_{\mathrm{b}}$ is the pond bottom albedo, and $\varepsilon_{\mathrm{W}}$ is the extinction coefficient of water, equal to the sum of the water absorption $\left(\alpha_{\mathrm{w}}\right)$ and scattering $\left(\sigma_{w}\right)$ coefficients:

$\varepsilon_{\mathrm{w}}=\alpha_{\mathrm{w}}+\sigma_{\mathrm{w}}$.

We use the data of Segelstein (1981) for the water absorption and the power law for the spectral scattering coefficient (Kopelevich, 1983):

$\sigma_{\mathrm{w}}(\lambda)=\sigma_{0}\left(\frac{\lambda_{0}}{\lambda}\right)^{4.3}, \sigma_{0}=1.7 \times 10^{-3} \mathrm{~m}^{-1}, \lambda_{0}=550 \mathrm{~nm}$.

Functions $f_{\text {in }}(x)$ and $f_{\text {out }}(x)$ are defined as

$f_{\text {in }}(x)=2 \int_{0}^{1} R_{\text {in }}\left(\mu^{\mathrm{w}}\right) \exp \left(-2 \frac{x}{\mu^{\mathrm{w}}}\right) \mu^{\mathrm{w}} \mathrm{d} \mu^{\mathrm{w}}$, 


$$
f_{\text {out }}(x)=2 \int_{0}^{1} T^{\mathrm{F}}(\mu) \exp \left(-\frac{x}{\mu^{\mathrm{w}}}\right) \mu \mathrm{d} \mu,
$$

(we changed notation used by Makshtas and Podgorny (1996), where $R_{\text {in }}$ is the internal reflectance of the water surface, and satisfy the relationship

$$
f_{\text {out }}(2 x)=n^{2}\left(2 E_{3}(2 x)-f_{\text {in }}(x)\right),
$$

where $E_{3}(x)$ is the integral exponential function of the third power:

$$
E_{3}(x)=\int_{1}^{\infty} \frac{e^{-x t}}{t^{3}} d t
$$

The first term in Eq. (1) describes the sun specular reflection from the water surface; the second one describes the light, multiply reflected between the pond bottom and its surface.

Albedo $A\left(\mu_{0}\right)$ given by Eq. (1) is the albedo at direct incidence (in climatology often called the black-sky albedo) and Makshtas and Podgorny (1996) restrict their consideration by this reflective property. However, two other characteristics, closely related to $A\left(\mu_{0}\right)$, are widely used both in climatology and in remote sensing. These are the albedo at diffuse incidence (white-sky albedo) and the bidirectional reflectance factor (BRF). Let us derive the structural formulas for these characteristics.

The albedo at diffuse incidence $A^{\mathrm{D}}$ (white-sky albedo) is defined as

$A^{\mathrm{D}}=\frac{1}{\pi} \int_{0}^{2 \pi} \int_{0}^{1} A\left(\mu_{0}\right) \mu_{0} \mathrm{~d} \mu_{0} \mathrm{~d} \varphi=2 \int_{0}^{1} A\left(\mu_{0}\right) \mu_{0} \mathrm{~d} \mu_{0}$

and can be found simply by integrating Eq. (1):

$A^{\mathrm{D}}=R^{\mathrm{FD}}+\frac{f_{\mathrm{out}}^{2}\left(\varepsilon_{\mathrm{w}} z\right) A_{\mathrm{b}}}{n^{2}\left(1-A_{\mathrm{b}} f_{\text {in }}\left(\varepsilon_{\mathrm{w}} z\right)\right)}$,

where $R^{\mathrm{FD}}$ is the Fresnel reflectance for the diffuse incidence.

The albedo at direct incidence is expressed through the bidirectional reflectance factor $R\left(\mu, \mu_{0}, \varphi\right)$ by the relation, analogous to Eq. (7):

$A\left(\mu_{0}\right)=\frac{1}{\pi} \int_{0}^{2 \pi} \int_{0}^{1} R\left(\mu, \mu_{0}, \varphi\right) \mu \mathrm{d} \mu \mathrm{d} \varphi$.

Comparing Eqs. (1) and (8) for albedos of direct and diffuse incidence and keeping in mind the relationships (7) and (9), we can immediately write the expression for the pond BRF:

$R=\frac{\pi}{\mu_{0}} R^{\mathrm{F}}\left(\mu_{0}\right) \delta\left(\mu-\mu_{0}\right) \delta(\varphi)$

$$
+\frac{T^{\mathrm{F}}(\mu) T^{\mathrm{F}}\left(\mu_{0}\right) A_{\mathrm{b}}}{n^{2}\left(1-A_{\mathrm{b}} f_{\text {in }}\left(\varepsilon_{\mathrm{w}} z\right)\right)} \exp \left(-\frac{\varepsilon_{\mathrm{w}} z}{\mu_{0}^{\mathrm{W}}}-\frac{\varepsilon_{\mathrm{w}} z}{\mu^{\mathrm{w}}}\right) .
$$

Equations (1), (9), and (11) give the structural formulas for the complete set of the pond reflective properties: albedos at direct and diffuse incidence and BRF. All the formulas are analytical and can be used straightforwardly, except Eqs. (4)(5) for functions $f_{\text {in }}(x)$ and $f_{\text {out }}(x)$, which should be calculated numerically. To speed up simulations one can calculate these functions once for a given set of wavelengths and then use a look-up table.

Note that Eqs. (1), (8), and (10) express the pond albedo and BRF in terms of the albedo of its bottom $A_{\mathrm{b}}$, which therefore is the main (and most indefinite) factor that determines the pond reflective properties. Therefore, the main questions arising here are as follows:

1. How is the pond bottom albedo expressed in terms of the inherent optical properties of sea ice and the ice layer thickness?

2. What are the main optical characteristics of under-pond ice that really determine the pond bottom albedo and, hence, the pond reflectance?

We address these questions in the following subsections.

\subsection{Inherent optical properties of under-pond ice}

Let us consider the inherent optical properties (IOPs) of under-pond ice that forms the pond bottom.

The IOPs of a medium used in the radiative transfer theory are the spectral scattering $\sigma(\lambda)$ and absorption $\alpha(\lambda)$ coefficients and the scattering phase function $p(\theta)$. In the following consideration (see Sect. 2.3), as in other radiative transfer theory applications (see, e.g., Davison, 1958; Chandrasekhar, 1960), the transport scattering coefficient $\sigma_{\mathrm{t}}$ is used:

$\sigma_{\mathrm{t}}=\sigma(1-g)$

where $g$ is the average cosine of the scattering angle $\theta$ :

$g=\langle\cos \theta\rangle=\frac{1}{2} \int_{0}^{\pi} p(\theta) \cos \theta \sin \theta \mathrm{d} \theta$.

The transport coefficient is useful in calculating the reflection and transmission by a scattering layer with a very forwardpeaked phase function, particularly if one is interested in the layer albedo, rather than the angular structure (BRF) of the reflected light (Zege et al., 1991).

Main factors that determine optical properties of sea ice are its microphysical structure and values of complex refractive indices of its constituents; the dispersion of complex refractive indices determines the spectral properties of sea ice.

As the volume concentration of air bubbles in sea ice is small - only up to $\sim 5 \%$ even in the extremely bubbly ice (Gavrilo and Gaitskhoki, 1970) - and the complex refractive 
index of brine is very close to that of ice (see Buiteveld et al., 1994; Warren and Brandt, 2008; and Sect. 2.2.2), we take the absorption coefficient of sea ice equal to that of solid ice. Impurities - sediment and organic pigments from sea water - could change absorption coefficients, particularly at shorter wavelengths. At this stage we neglect their effect, keeping in mind that their absorption spectra can be added, if necessary.

The scattering takes place at inhomogeneities in sea ice and is mainly caused by air bubbles and brine inclusions (Mobley et al., 1998; Light, 2010). Another source of scattering could be salt crystals, but they precipitate at low temperatures and are not observed in summer ice, where melt ponds are formed: precipitation temperatures for mirabilite $\left(\mathrm{Na}_{2} \mathrm{SO}_{4} \cdot 10 \mathrm{H}_{2} \mathrm{O}\right)$ and hydrohalite $\left(\mathrm{NaCl} \cdot 2 \mathrm{H}_{2} \mathrm{O}\right)$ crystals are -8 and $-23^{\circ} \mathrm{C}$, respectively (Light et al., 2003).

\subsubsection{Air bubbles}

The upper layer of sea ice $(20-30 \mathrm{~cm})$ usually contains a significant amount of air bubbles (Gavrilo and Gaitskhoki, 1970; Mobley et al., 1998), with volume concentration which can reach values of $5 \%$ and which decreases with depth. (We do not consider here the surface scattering layer that is formed on top of sea ice during the water drainage process.) Air bubbles in sea ice are mostly spherical (Gavrilo and Gaitskhoki, 1970; Mobley et al., 1998; Light, 2010). Light (2010) gives the following size distribution for bubbles in first-year sea ice:

$N(r) \sim r^{-1.5}, \quad 4 \mu \mathrm{m} \leq r \leq 70 \mu \mathrm{m}$.

For this distribution the effective radius is $R_{\mathrm{a}}=42.55 \mu \mathrm{m}$. Gavrilo and Gaitskhoki (1970) report the presence of much larger bubbles in the bubbly ice: from 0.1 to $2 \mathrm{~mm}$ with the exponent -1.24 (the effective radius is $1.28 \mathrm{~mm}$ ).

However, since air bubbles in ice are optically hard (the refractive index of air differs strongly from that of ice) and do not absorb light, scattering by bubbles of this size range is described by the laws of geometrical optics. Thus, the scattering characteristics do not depend on the bubble size (unless considering the strictly forward and backward directions), and the shape of the size distribution is also insignificant. Particularly, the scattering efficiency $Q_{\text {sca }}$ in this case equals 2 and the phase function can be easily calculated with the Mie formulas for any type of size distribution, e.g., for the one given in Eq. (13).

The refractive index of air (relative to ice) in the interval $0.35-0.95 \mu \mathrm{m}$ changes from 0.755 to 0.768 with average value of 0.763 within this interval. The corresponding average cosine $g$ of the scattering angle, obtained with the Mie calculations, takes values from 0.851 to 0.865 with the mean value of 0.860 , and therefore the spectral variability does not exceed $2 \%$.

\subsubsection{Brine inclusions}

The main features of brine inclusions are the following: they are optically soft, i.e., their refractive index $n_{\mathrm{b}}$ (brine relative to ice) is close to unity; their size is large (comparing to the wavelength); and their shape is strongly irregular (here we do not consider drained pockets and channels that contain air). Under these assumptions we can apply the WentzelKramers-Brillouin approximation for irregularly shaped particles (Malinka, 2015) to describe scattering properties of brine inclusions.

The size of brine inclusions, which can be on the order of several millimeters, is so much larger than the wavelength of visible light that their optical properties can be considered in the limit of infinitely large particles, despite their refractive index $n_{\mathrm{b}}$ being close to unity:

$n_{\mathrm{b}}-1 \ll 1$.

At this limit the size distribution is also insignificant and the scattering efficiency $Q_{\text {sca }}$ is independent of the wavelength:

$Q_{\text {sca }}=2$.

The scattering phase function of optically soft particles can be approximated according to Malinka (2015) by

$p(\theta)=\frac{2 x^{2}\left(1+\mu^{2}\right)}{\left(1+2 x^{2}(1-\mu)\right)^{2}}$,

where $\mu=\cos \theta$ and $x$ is the optical particle size (dimensionless), which for large particles equals

$x=\frac{n_{\mathrm{b}}+1}{n_{\mathrm{b}}-1} \sqrt{\frac{Q_{\text {sca }}}{8}}$.

In view of Eqs. (15) and (16), we can write

$x=\frac{1}{n_{\mathrm{b}}-1}$.

The average cosine $g$ of the phase function (14) is

$1-g=\frac{\log 2 x-1}{x^{2}}$.

Figure 1 demonstrates the spectral dependence of the refractive index of water relative to ice. We used the data by Warren and Brandt (2008) for ice. The refractive index of water is taken from Hale and Querry (1973), Segelstein (1981), Daimon and Masumura (2007), and Kedenburg et al. (2012) for distilled water, from the formula of Quan and Fry (1995) for brine of zero salinity, i.e., fresh water, at temperature $0{ }^{\circ} \mathrm{C}$, and from the formula of Frisvad (2009), which is based mainly on Quan and Fry (1995) and the measurements by Maykut and Light (1995), for brine with equilibrium salinity at temperatures $-2,-4$, and $-6^{\circ} \mathrm{C}$. The earlier data 


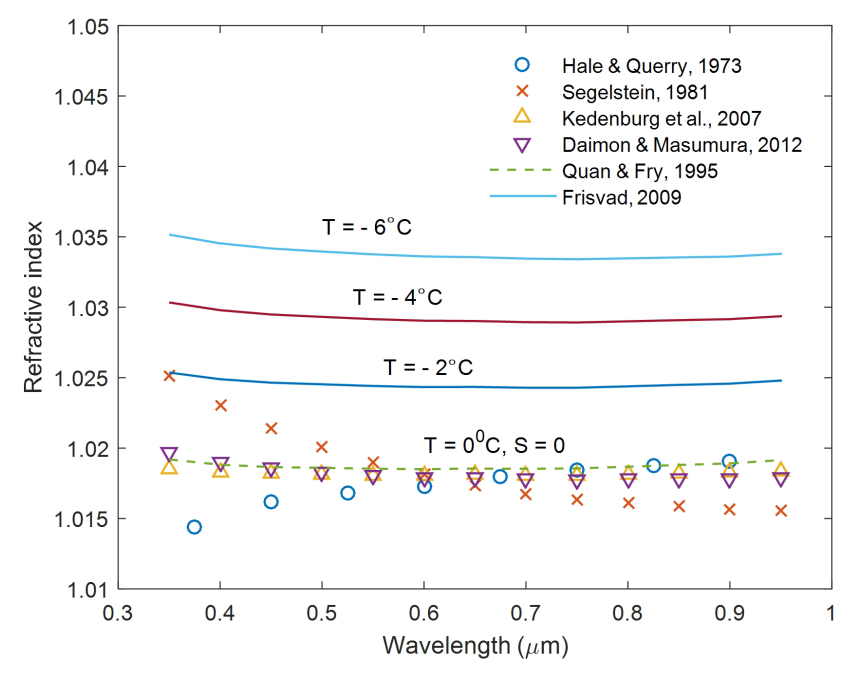

Figure 1. Spectra of the relative refractive index "water to ice": distilled water (symbols), fresh water at $0^{\circ} \mathrm{C}$ (dashes), and brine with equilibrium salinity at different temperatures (solids).

(Hale and Querry, 1973; Segelstein, 1981) clearly demonstrate the spectral dependences, their dispersions being opposite. In contrast, the newer data do not demonstrate such dependence: according to the more modern data the refractive index (relative to ice) of water, including brine, is almost spectrally neutral. This question is important when describing the light scattering by brine inclusions in ice, because the transport scattering coefficient is determined mainly by the value $\left(n_{\mathrm{b}}-1\right)^{2}$ (see Eqs. 12 and 19-20). Finally, according to the newer data we will accept that the relative refractive index of brine, and therefore the transport scattering coefficient of brine inclusions, is spectrally neutral. For example, $n=1.024$ for temperature $-2{ }^{\circ} \mathrm{C}$ and, according to Eqs. (19)-(20), $g=0.998$. Note that the value of $g$ in this model is significantly greater than that used in many other studies, e.g., in Mobley et al. (1998) or Light et al. (1998).

\subsubsection{Inherent optical properties of sea ice}

Light-scattering properties of sea ice are a combination of those of brine inclusions and air bubbles. The total and transport scattering coefficients are the sum of the respective values:

$\sigma=\sigma_{\mathrm{b}}+\sigma_{\mathrm{a}}$,

$\sigma_{\mathrm{t}}=\sigma_{\mathrm{b}}^{\mathrm{t}}+\sigma_{\mathrm{a}}^{\mathrm{t}}$.

We denote the values related to brine inclusions with the subscript $b$ and to air bubbles with the subscript $a$. The phase function and the average cosine are the linear combination of the respective values:

$$
\begin{aligned}
& p(\theta)=\frac{\sigma_{\mathrm{b}}}{\sigma} p_{\mathrm{b}}(\theta)+\frac{\sigma_{\mathrm{a}}}{\sigma} p_{\mathrm{a}}(\theta), \\
& 1-g=\frac{\sigma_{\mathrm{b}}}{\sigma}\left(1-g_{\mathrm{b}}\right)+\frac{\sigma_{\mathrm{a}}}{\sigma}\left(1-g_{\mathrm{a}}\right)=\frac{\sigma_{\mathrm{t}}}{\sigma} . l a b e l e q 24
\end{aligned}
$$

Once $g_{\mathrm{a}}$ and $g_{\mathrm{b}}$ are known (e.g., at $-2^{\circ} \mathrm{C} g_{\mathrm{a}}=0.86, g_{\mathrm{b}}=$ 0.998 ), the resulting $g$ depends only on the proportion of fractions $a$ and $b$.

Generally, the IOPs of sea ice depend on its microstructure. In view of the fact that both bubble and brine inclusion size is much larger than the wavelength, the scattering coefficient equals

$\sigma_{j}=2 \psi_{j}(j=a, b)$,

where $\psi$ is the specific cross-sectional area of inclusions (air or brine):

$\psi_{j}=\left\langle S_{\perp}\right\rangle_{j} N_{j}=\frac{3 C_{j}^{\mathrm{V}}}{4 R_{j}}$.

Here subscript $j$ shows the fraction number, $\left\langle S_{\perp}\right\rangle_{j}$ is the average cross-sectional area of $j$ inclusions, $R_{j}$ their effective radius, $N_{j}$ and $C_{j}^{\mathrm{V}}$ are their numeric and volume concentration, respectively.

The phase function (and consequently its average cosine $g$ ) can be characterized by the ratio of volume concentration air-to-brine $C_{\mathrm{a}}^{\mathrm{V}} / C_{\mathrm{b}}^{\mathrm{V}}$, if their effective radii are determined. However, as the morphology of sea ice can vary drastically with place and time, the more convenient way to characterize the ratio of air and brine fractions is to use the ratio of their transport coefficients $\sigma_{\mathrm{a}}^{\mathrm{t}} / \sigma_{\mathrm{b}}^{\mathrm{t}}$. This ratio is related to the ratio of volume concentrations as

$\frac{\sigma_{\mathrm{a}}^{\mathrm{t}}}{\sigma_{\mathrm{b}}^{\mathrm{t}}}=\frac{1-g_{\mathrm{a}}}{1-g_{\mathrm{b}}} \frac{R_{\mathrm{b}}}{R_{\mathrm{a}}} \frac{C_{\mathrm{a}}^{\mathrm{V}}}{C_{\mathrm{b}}^{\mathrm{V}}}$.

Figure 2 presents the phase function of mixtures with different air-to-brine fractions ratio.

We conclude that the phase function (and consequently $g$ ) of sea ice is spectrally neutral in the visible and near-IR range. In virtue of Eq. (25), the scattering coefficient $\sigma$ is also spectrally neutral. Consequently, the transport scattering coefficient $\sigma_{\mathrm{t}}$ is also spectrally neutral and can serve as a scalar parameter that characterizes scattering in sea ice.

For example, Light (2010) gives the value of $110 \mathrm{~m}^{-1}$ for $\psi_{\mathrm{b}}$, the specific cross-sectional area of brine inclusions, for a sample of typical first-year ice at $-15^{\circ} \mathrm{C}$. This value can grow up to $400 \mathrm{~m}^{-1}$ when the ice warms. The estimate, made by Light (2010) for the brine volume concentration in the same sample, gives the values from 1.2 to $1.9 \%$. This allows us to estimate the effective radius of brine inclusions as $R_{\mathrm{b}} \approx 100 \mu \mathrm{m}$ and the lower value of the transport scattering coefficient as $\sigma_{\mathrm{b}}^{\mathrm{t}} \approx 0.4 \mathrm{~m}^{-1}$. The latter value can be used to estimate the transport scattering coefficient of rather transparent sea ice. Light (2010) gives the mean value $\sigma_{\mathrm{b}}^{\mathrm{t}} \approx 9 \mathrm{~m}^{-1}$; the difference apparently comes from the different values of $g$, whose mean value is taken by Light (2010) as 0.977 vs. 0.998 used in this work.

The bubbly ice reported by Gavrilo and Gaitskhoki (1970) has $\sigma_{\mathrm{a}}^{\mathrm{t}} \approx 8 \mathrm{~m}^{-1}$. This value can be used for estimation of 


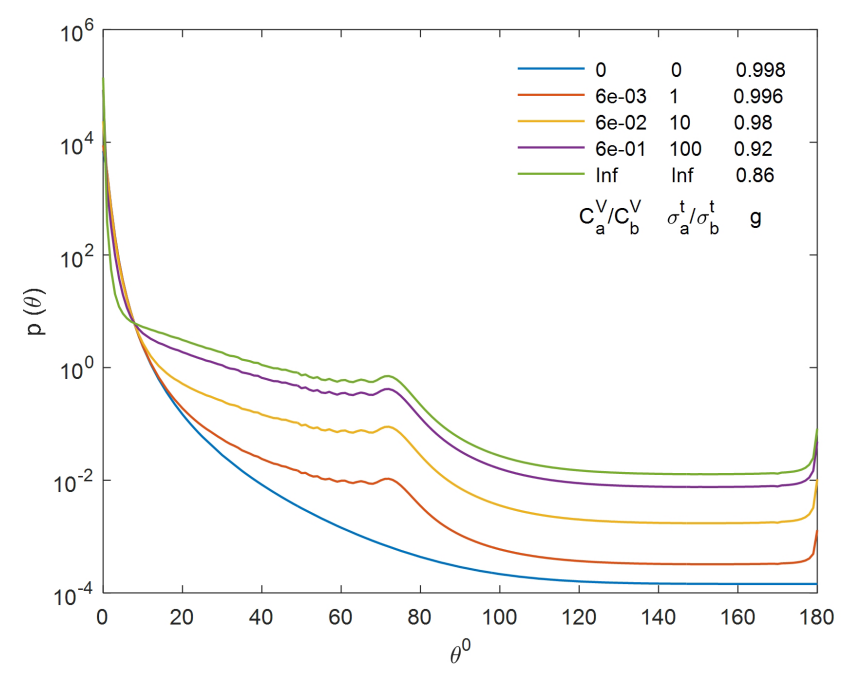

Figure 2. Phase functions of the mixture of air bubbles and brine inclusions at $-2{ }^{\circ} \mathrm{C}$ with different fraction ratio $C_{\mathrm{a}} \mathrm{V} / C_{\mathrm{b}}^{\mathrm{V}}$. The ratio of transport scattering coefficients $\sigma_{\mathrm{a}}^{\mathrm{t}} / \sigma_{\mathrm{b}}^{\mathrm{t}}$ and the average cosine $g$ are also shown. The effective sizes are $R_{\mathrm{a}}=42.55 \mu \mathrm{m}, R_{\mathrm{b}}=100 \mu \mathrm{m}$.

the upper bound for the transport scattering coefficient of sea ice. On the whole, the range of its values can be estimated by order as $0.1-10 \mathrm{~m}^{-1}$. Mobley et al. (1998) give a typical value of $4 \mathrm{~m}^{-1}$ for the transport scattering coefficient of sea ice.

\subsection{Bottom albedo}

If both the absorption and transport scattering coefficients are known, the albedo of a layer can be calculated within the two-stream approximation, which is widely used for practical calculations:

$A_{\mathrm{b}}=A_{0} \frac{1-\exp (-2 \gamma \tau)}{1-A_{0}^{2} \exp (-2 \gamma \tau)}$,

where $A_{0}$ is the albedo of the semi-infinite layer with the same optical characteristics, $\gamma$ is the asymptotic attenuation coefficient, and $\tau$ is the layer optical thickness. The version of the two-stream approximation developed by Zege et al. (1991) expresses these characteristics as follows:

$A_{0}=1+t-\sqrt{t(t+2)}$,

$\gamma=\frac{3}{4} \frac{\sigma_{\mathrm{t}}}{\sigma_{\mathrm{t}}+\alpha_{\mathrm{i}}} \sqrt{t(t+2)}$

$\tau=\left(\sigma_{\mathrm{t}}+\alpha_{\mathrm{i}}\right) H$,

with

$t=\frac{8 \alpha_{\mathrm{i}}}{3 \sigma_{\mathrm{t}}}$,

where $\alpha_{\mathrm{i}}$ is the ice absorption coefficient; $H$ is the ice layer thickness.
The two-stream approximation in the version given in Zege et al. (1991) has a wide range of applicability and can be used both for strongly and weakly absorbing media, for optically thin and thick layers. Hence, this approximation can be applied to all the variety of melt ponds: from young ponds, which are light blue and have comparatively optically thick under-pond ice, to mature dark ones, where under-pond ice is optically thin.

\subsection{Model outline}

Thus, in the assumption of a Lambertian bottom and plane parallel geometry, which applies in the absence of strong wind, i.e., calm pond surface, the spectral reflection of ponds is determined by two values: water layer depth $z$ and the albedo of the pond bottom $A_{\mathrm{b}}$. The latter, in turn, depends on the transport scattering coefficient of under-pond ice $\sigma_{\mathrm{t}}$ and its geometric thickness $H$ (or the transport optical thickness $\sigma_{\mathrm{t}} H$ ). Note that only value $\alpha_{\mathrm{i}}$ in Eqs. (28)-(32) has a spectral behavior, while the others $-\sigma_{\mathrm{t}}$ and $H$ - are scalars.

Thus, in the absence of pollutants just three parameters determine the pond spectral reflectance: namely, the transport scattering coefficient $\sigma_{\mathrm{t}}$ and geometric thickness $H$ of the under-pond ice and water layer depth $z$. This statement is confirmed by the coincidence of measured and modeled spectra demonstrated below. The outlined model of a melt pond is shown in short in Table 1.

\section{Illumination conditions}

\subsection{Atmospheric correction}

Correct processing of the reflection measurement results requires the correct modeling of the illumination conditions. This is especially important for measurements in the Arctic, because of the low sun and the bright surface. When the sky is overcast, the incident light is close to diffuse, even if the solar disk is visually observed (Malinka et al., 2016b). In this case the measured albedo is the white-sky one. However, when the sky is clear and the sun is near the horizon, the direct solar flux is comparable to the diffuse flux from the sky, so the measured (blue-sky) albedo value is a mixture of those at direct (black-sky) and diffuse (white-sky) incidence. The black-sky albedo increases when the sun is approaching the horizon, so the difference between the white- and black-sky albedos is most essential at oblique incidence (see Fig. 3). The problem of the correct interpretation of the measured blue-sky albedo is considered in detail in Malinka et al. (2016b) for a homogeneous surface. However, the albedo of a melt pond can differ significantly from that of the surrounding background, e.g., white ice or snow. Some estimation for this case is given below.

Let $R, A\left(\mu_{0}\right)$ and $A^{\mathrm{D}}$ be, as before, the BRF, black-sky, and white-sky albedo of a melt pond, respectively. Let the surrounding background be Lambertian with albedo $r_{\mathrm{b}}$. Then 
Table 1. Melt pond characteristics.

\begin{tabular}{lll}
\hline Layer & Predefined characteristics & Variable characteristics \\
\hline Air-water boundary (AW) & $\begin{array}{l}\text { Spectral refractive index } n \text {; Fresnel reflectance } R^{\mathrm{F}} \\
\text { and transmittance } T^{\mathrm{F}}\end{array}$ & No \\
\hline Water & $\begin{array}{l}\text { Water absorption coefficient } \alpha_{\mathrm{W}} \text { (spectral); } \\
\text { Rayleigh scattering coefficient } \sigma_{\mathrm{W}}(\text { in the law of extinction only) }\end{array}$ & Pond depth $z$ \\
\hline $\begin{array}{l}\text { Under-pond ice layer } \\
\text { (pond bottom) }\end{array}$ & $\begin{array}{l}\text { Ice absorption coefficient } \alpha_{\mathrm{i}}(\text { spectral); } \\
\text { scattering within the two-stream and transport approximations }\end{array}$ & $\begin{array}{l}\text { Transport scattering coefficient } \sigma_{\mathrm{t}} \\
\text { Thickness } H\end{array}$ \\
\hline
\end{tabular}

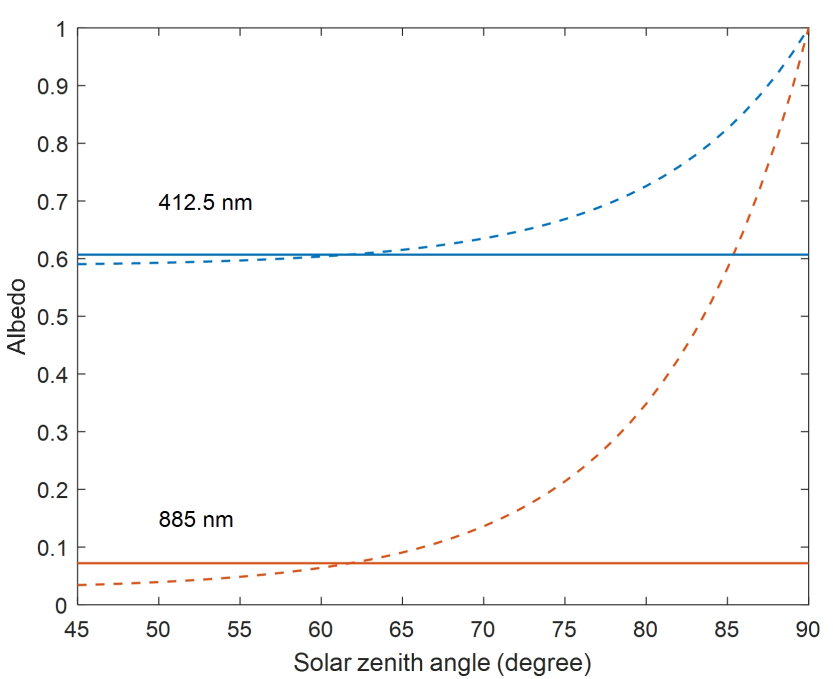

Figure 3. Black-sky albedo of a light melt pond $\left(z=17 \mathrm{~cm}, \sigma_{\mathrm{t}}=\right.$ $3.2 \mathrm{~m}^{-1}, H=1.25 \mathrm{~m}$ ) vs. the angle of incidence (dashed). The white-sky albedo values are shown in solid.

the brightness of the incident radiance can be estimated as (Malinka et al., 2016b)

$B_{\downarrow}=\left[t_{0}\left(\mu_{0}\right) \hat{\delta}+t_{\mathrm{d}}\left(\mu_{0}\right)+\frac{r_{\mathrm{a}} r_{\mathrm{b}}}{1-r_{\mathrm{a}} r_{\mathrm{b}}} T\left(\mu_{0}\right)\right] \frac{E_{0} \mu_{0}}{\pi}$,

where $t_{0}\left(\mu_{0}\right)$ and $t_{\mathrm{d}}\left(\mu_{0}\right)$ are the direct and diffuse atmosphere transmittances, $\hat{\delta}=\pi \delta\left(\mu-\mu_{0}\right) \delta\left(\varphi-\varphi_{0}\right) / \mu_{0}$ is the identity operator $\left(\delta(x)\right.$ is the Dirac delta function), $T\left(\mu_{0}\right)=$ $t_{0}\left(\mu_{0}\right)+t_{\mathrm{d}}\left(\mu_{0}\right)$ is the atmosphere transmittance at direct incidence, and $r_{\mathrm{a}}$ is the atmosphere bihemispherical reflectance at incidence from below. $E_{0}$ is the extraterrestrial solar irradiance.

Thus, the light flux incident to a melt pond is

$F_{\downarrow}=\frac{T\left(\mu_{0}\right)}{1-r_{\mathrm{a}} r_{\mathrm{b}}} E_{0} \mu_{0}$.

The radiance of light reflected by pond follows from Eq. (33):

$$
\begin{aligned}
& B_{\uparrow}= \\
& \quad\left[R\left(\mu, \mu_{0}, \varphi\right) t_{0}\left(\mu_{0}\right)+A(\mu)\left(t_{\mathrm{d}}\left(\mu_{0}\right)+\frac{r_{\mathrm{a}} r_{\mathrm{b}}}{1-r_{\mathrm{a}} r_{\mathrm{b}}} T\left(\mu_{0}\right)\right)\right]
\end{aligned}
$$

$$
\begin{aligned}
& \frac{E_{0} \mu_{0}}{\pi}= \\
& {\left[\left(R\left(\mu, \mu_{0}, \varphi\right)-A(\mu)\right) t_{0}\left(\mu_{0}\right)+A(\mu) \frac{T\left(\mu_{0}\right)}{1-r_{\mathrm{a}} r_{\mathrm{b}}}\right] \frac{E_{0} \mu_{0}}{\pi} .}
\end{aligned}
$$

Therefore the reflected flux is

$$
F_{\uparrow}=\left[\left(A\left(\mu_{0}\right)-A^{\mathrm{D}}\right) t_{0}\left(\mu_{0}\right)+A^{\mathrm{D}} \frac{T\left(\mu_{0}\right)}{1-r_{\mathrm{a}} r_{\mathrm{b}}}\right] E_{0} \mu_{0} .
$$

For the measured value of the blue-sky albedo $A^{\text {blue }}$ it follows that

$A^{\text {blue }}=\frac{F_{\uparrow}}{F_{\downarrow}}=\frac{\left(A\left(\mu_{0}\right)-A^{\mathrm{D}}\right) t_{0}\left(\mu_{0}\right)\left(1-r_{\mathrm{a}} r_{\mathrm{b}}\right)+A^{\mathrm{D}}}{T\left(\mu_{0}\right)}$.

The equation for the blue-sky albedo can be written as a linear combination of the black and white-sky albedos:

$A^{\text {blue }}=w A\left(\mu_{0}\right)+(1-w) A^{\mathrm{D}}$,

with the proportion of direct radiance $w$ :

$w=\frac{t_{0}\left(\mu_{0}\right)}{T\left(\mu_{0}\right)}\left(1-r_{\mathrm{a}} r_{\mathrm{b}}\right)$.

Factor $\left(1-r_{\mathrm{a}} r_{\mathrm{b}}\right)$ is responsible for multiple reflections between the atmosphere and surrounding background.

Modeled albedo spectra of a light melt pond (a pond with high reflectance) at different illumination conditions are shown in Fig. 4. The angle of incidence is $80^{\circ}$ (the sun elevation is $10^{\circ}$ ). The interval of albedo changes is limited by the values of white and black-sky ones. Also shown are the bluesky albedos for clear sky and for sky with thin cirrus layer (with optical thickness of 0.1). Both are considered with different surrounding backgrounds: perfectly black $\left(r_{\mathrm{b}}=0\right)$ and white $\left(r_{\mathrm{b}}=1\right)$. As seen from Fig. 4 , the effect of background is negligible (only small difference between the dots and the solid blue curve and between the crosses and the blue dashed curve), so the results of melt pond albedo measurements can be processed without a priori knowledge of the albedo of the surrounding background.

\subsection{IR reflectance}

In contrast to the visible range, ice and water absorb a significant amount of light in the IR: a layer of ice a few centimeters thick or water completely absorbs radiation in the 


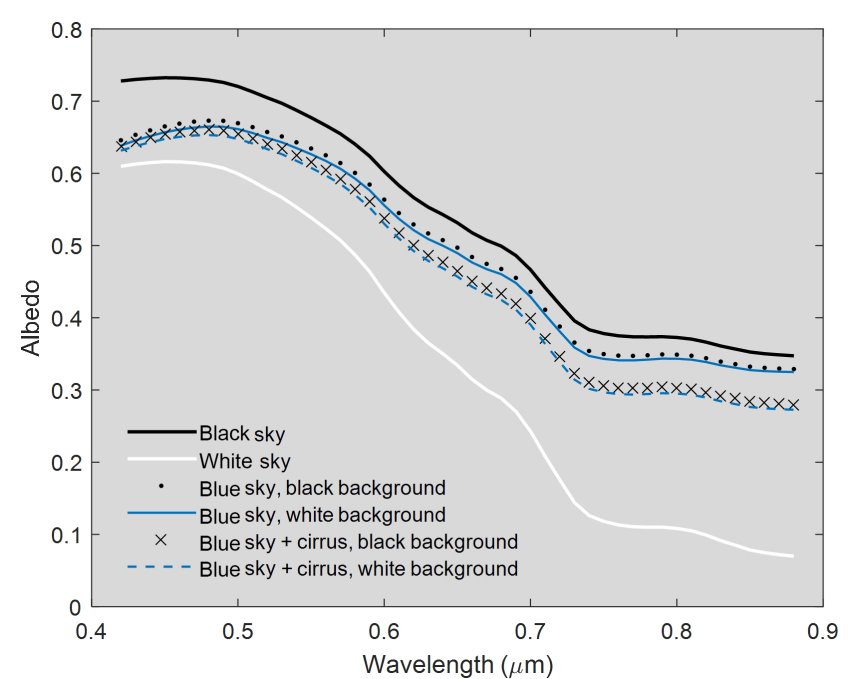

Figure 4. Modeled spectra of melt pond albedos at various sky conditions and background albedo at sun elevation $10^{\circ}$.

infrared range. Thus the melt pond optical response in the IR is restricted to the Fresnel reflection by the pond surface. In contrast, ice grains in the surface scattering layer are of the order of millimeters in size (and even smaller in snow). Due to this fact, specific features of the spectral behavior of the imaginary part $\kappa$ of the refractive index of ice can appear. In particular, $\kappa$ has a local minimum at $1.1 \mu \mathrm{m}$, which provides a slight peak of reflection in the interval $1.05-1.11 \mu \mathrm{m}$ (Wiscombe and Warren, 1980). Figure 5 shows an example of the modeled albedo's spectral dependence for white ice, snow, and a melt pond. It clearly demonstrates that for wavelengths longer than $0.9 \mu \mathrm{m}$ the melt pond reflection is restricted by the Fresnel reflection to a constant value, while snow and white ice demonstrate a local maximum at $1.1 \mu \mathrm{m}$. Thus, this slight peak can serve as a criterion for determining if a spectrum is taken entirely from an open pond or partially from snow/ice surface. If this peak is observed in a measured spectrum, it clearly indicates the presence of ice grains (of white ice or snow) in the receiver field of view.

\subsection{Measurement geometry}

In the description of the field data used in this study, most sky conditions were reported as overcast. Only a few measurements were taken under clear-sky conditions. Scattered clouds were not reported at all in the measurement series considered. In the cases of overcast sky, the measured albedo was interpreted as the white-sky one. In the clear-sky cases, the Rayleigh atmosphere with the Arctic background aerosol (Tomasi et al., 2007) was assumed. In this case the solar incidence angle was determined from the pond reflection in the IR: at the interval $1.25-1.3 \mu \mathrm{m}$ (preferably) or $0.85-0.9 \mu \mathrm{m}$, if data at the former interval are not available. As the IR signal (both incident and reflected) is quite weak and hence some

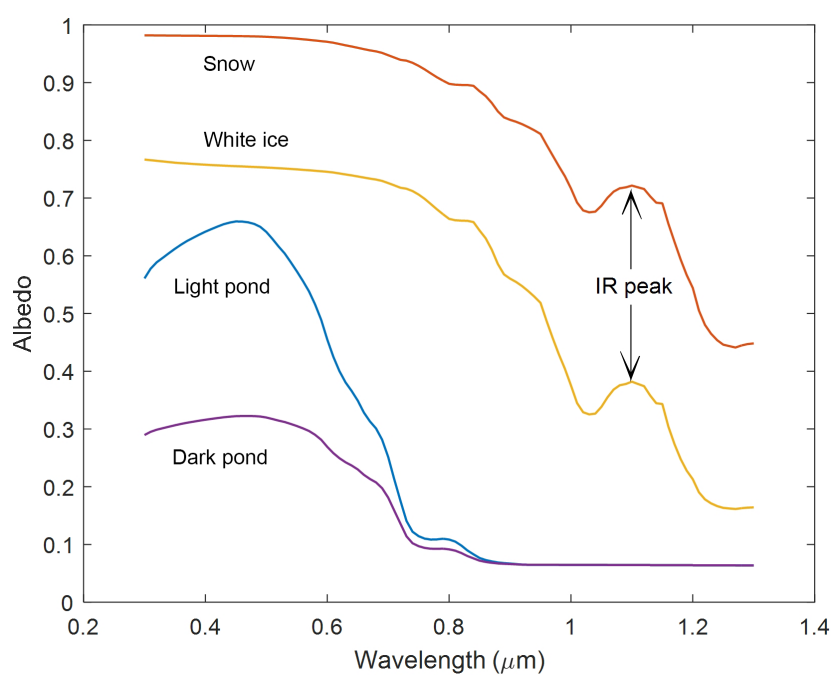

Figure 5. Typical spectral albedo of melt ponds, snow, and white ice, calculated for the following parameters: light pond - depth $z$ is $20 \mathrm{~cm}, \sigma_{\mathrm{t}}=4 \mathrm{~m}^{-1}, H=1.25 \mathrm{~m}$ (transport optical depth is 5); dark pond - depth $z$ is $20 \mathrm{~cm}, \sigma_{\mathrm{t}}=2 \mathrm{~m}^{-1}, H=0.5 \mathrm{~m}$ (transport optical depth is 1 ); white ice - the effective grain size is $2 \mathrm{~mm}$ and optical depth is 12 ; snow - the effective grain size is $0.2 \mathrm{~mm}$ and optical depth is 200 (see Malinka et al., 2016a, for details).

noise is always noticeable, we average the signal over one of the abovementioned intervals. The pond reflectance in these IR intervals is completely determined by the Fresnel reflection of its upper boundary. Atmosphere scattering in the IR is negligible (especially at $1.3 \mu \mathrm{m}$ ), so the incident light is unidirectional. In this situation the solar incident angle can be calculated through the Fresnel equations.

\section{Model verification}

Three different datasets with in situ field measurements were used for the evaluation of the pond model. They are described in the next subsections.

\subsection{Polarstern-2012}

Measurements of the spectral albedo of different sea-ice surfaces were carried out during the R/V Polarstern cruise ARK-XXVII/3 (2 August-8 October 2012). Only in the second half of the cruise did the vessel leave the marginal ice zone and enter the ice pack. The ice thickness varied from 0.5 to $3 \mathrm{~m}$ with an average of $1-1.5 \mathrm{~m}$. Melt ponds were observed in August. They were both open (with no skim ice) and frozen over (with a skim of ice), sometimes snow covered. The data were collected during stations, when the vessel was parked at an ice floe for several days. This gave the possibility to obtain several-day data sequences of melting sea ice and evolving melt ponds at the same location. The stations, where ponds were observed, were located from 
(a)
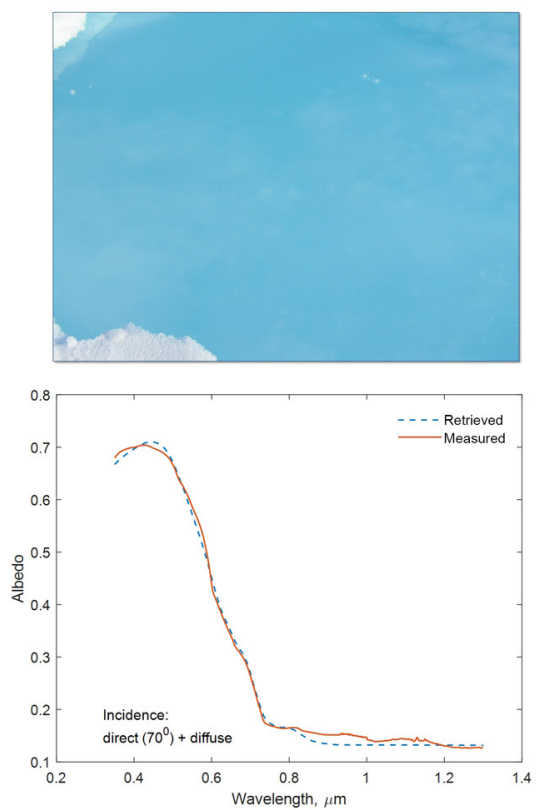

(b)
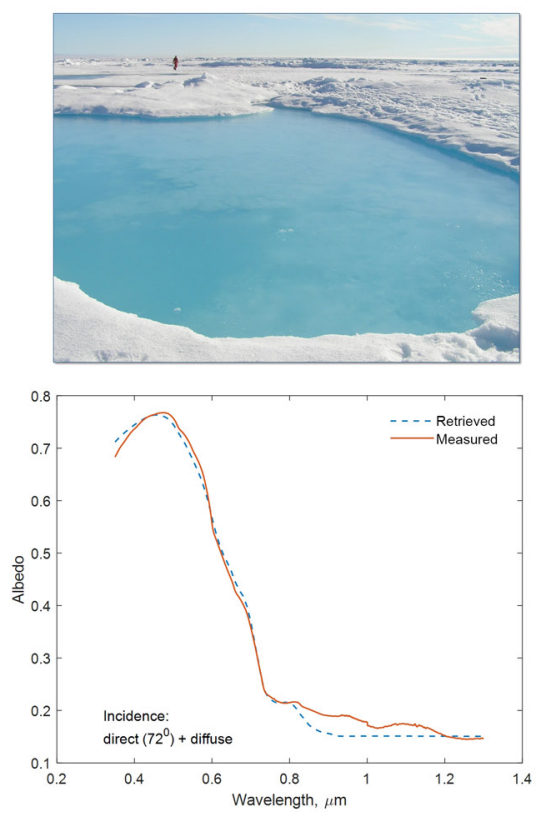

(c)
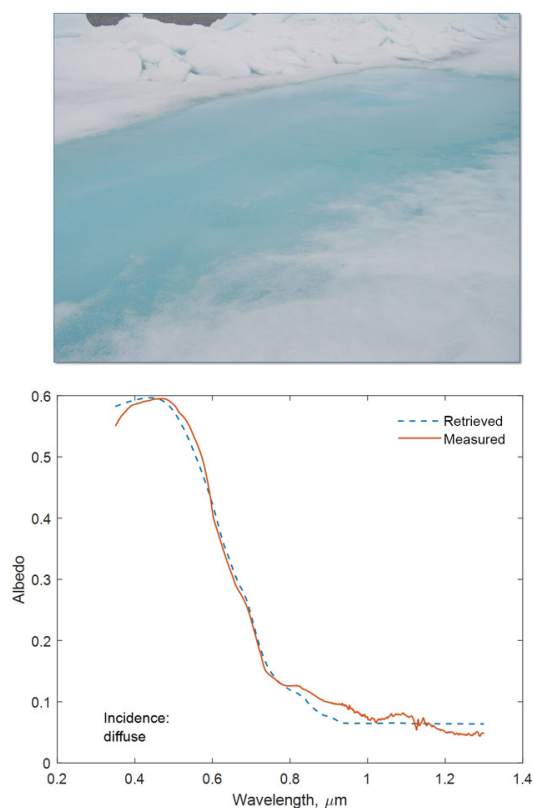

Figure 6. Light frozen (2-3 cm layer of ice) blue ponds. Polarstern-2012, Stations 1 (a, b) and 3 (c).

$84^{\circ} 3^{\prime} \mathrm{N}, 31^{\circ} 7^{\prime} \mathrm{E}$ to $82^{\circ} 54^{\prime} \mathrm{N}, 129^{\circ} 47^{\prime} \mathrm{E}$. For more information about the cruise, including the coordinates and dates of the stations, see Boetius and ARK-XXVII/3 Shipboard Scientific Party (2012) and Istomina et al. (2016, 2017).

The ASD FieldspecPro III spectroradiometer used for these measurements has three different sensors that provide measurements from 350 to $2500 \mathrm{~nm}$ with the spectral resolution of $1.0 \mathrm{~nm}$. A sensor measures the light signal supplied by a fiber optical probe, which collects light reflected by a $10 \mathrm{~cm} \times 10 \mathrm{~cm}$ Spectralon white plate. The plate was held at about $1 \mathrm{~m}$ above the surface and was directed first towards the measured surface and then towards the sky. The ratio of these two measurements gives the hemispherical reflectance (albedo) of the surface. For some cases the water depth and ice thickness within the pond were measured.

For the model verification we considered the melt pond albedo in the spectral interval $0.35-1.3 \mu \mathrm{m}$. The retrieval procedure implies searching for the pond parameter values shown in Table 1. These three parameters comprise a 3-D vector, which is varied according to the Newton-Raphson method to provide the best fit (in the sense of the least squares) of the measured and modeled spectra (for details of the method see Zege et al., 2015). For the cases where the pond depth and underlying ice thickness were measured, the pond parameters retrieved were compared to the measured ones.

Some ponds were frozen over, i.e., they had a layer of newly formed ice on top of their surface. It is evident that a layer of flat, transparent ice at the pond surface practically does not change pond reflection, so we consider the ponds with ice crust in the same manner as open ones. However, if the upper ice layer is bubbly or snow covered, the pond reflectance can change drastically: the pond gets brighter and may become indistinguishable from the surrounding ice in the visible range. These snow-covered ponds would require other means for their characterization. We exclude such cases from consideration.

Figures 6-9 present photos of different ponds and their reflectance spectra, measured and simulated with the retrieved parameters (denoted as "retrieved" in the legend).

Figure 6 shows the photos as well as modeled and measured spectra of light-blue melt ponds, which have a uniform bottom on thick first-year ice under clear and cloudy skies, measured in the central Arctic on 10 and 22 August 2012, respectively. The albedo values are extraordinarily high. This could be related to the fact that the ponds are frozen over with a $2-3 \mathrm{~cm}$ layer of ice, which is likely not perfectly transparent. Figure 7 shows three cases of frozen over blue ponds with heterogeneous bottom under overcast skies measured on 11 and 22 August 2012, respectively. One can see darker parts in the ponds, which result from sea-ice melting from the lower boundary or lower bubble content. Figure 8 presents dark open melt ponds on thinner first-year ice under overcast skies, all measured on 26 August 2012. The albedo of these ponds is much lower than that of the previous ones: from about 0.07 to 0.14 in the visible and about 0.05 in the IR. Figure 9 presents two cases of light-blue ponds, both measured on 26 August 2012, and a dark pond contaminated with algae aggregates measured on 21 August 2012, all under overcast skies. Surprisingly, the spectrum of the pond with algae is re- 
(a)
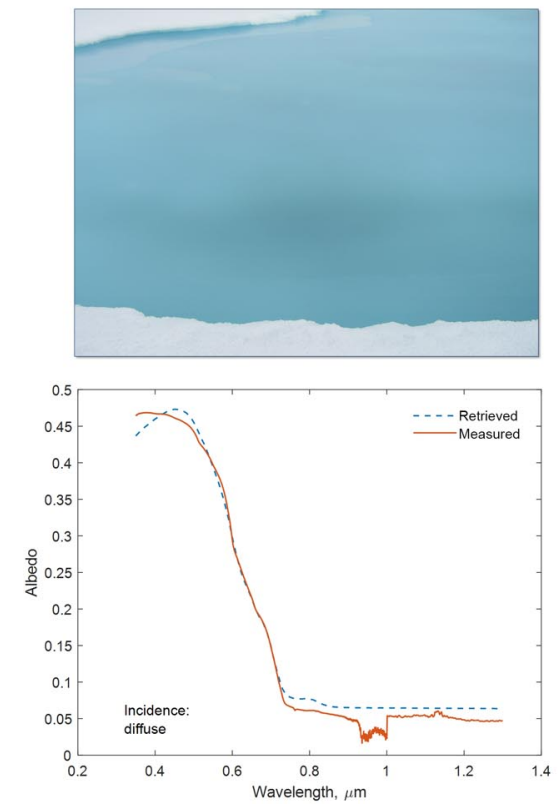

(b)
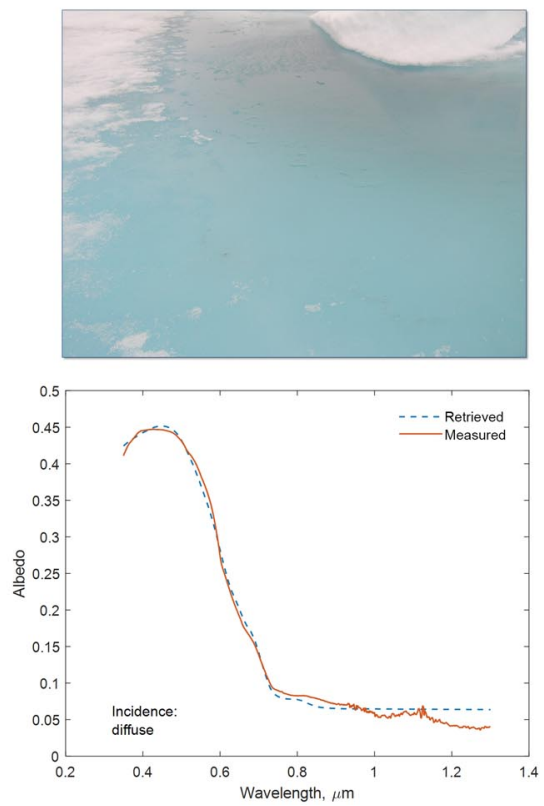

(c)
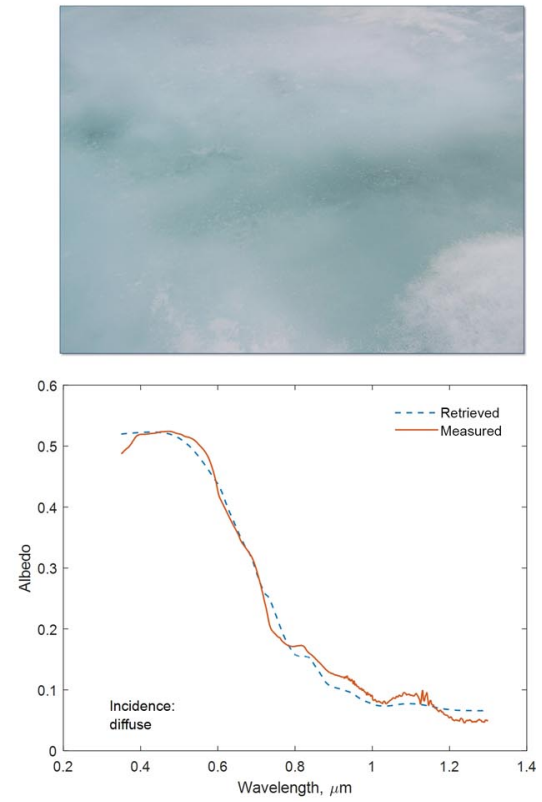

Figure 7. Frozen blue ponds. Polarstern-2012, Stations 1 (a) and 3 (b, c). The left pond is heterogeneous. The sensor was placed approximately in the center of the photograph, about $1 \mathrm{~m}$ from the pond edge.

(a)
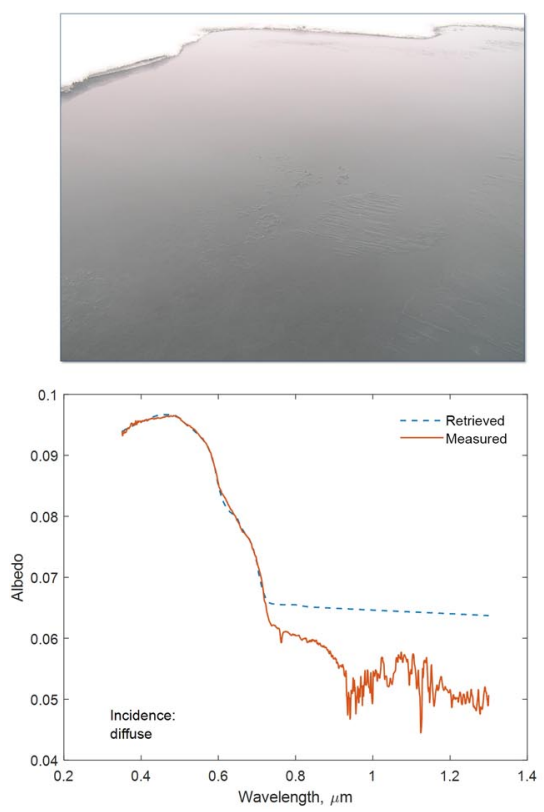

(b)
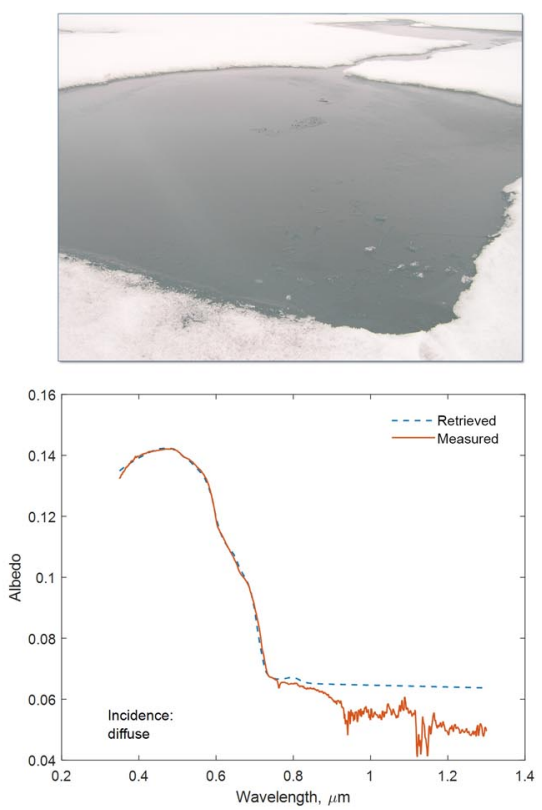

(c)
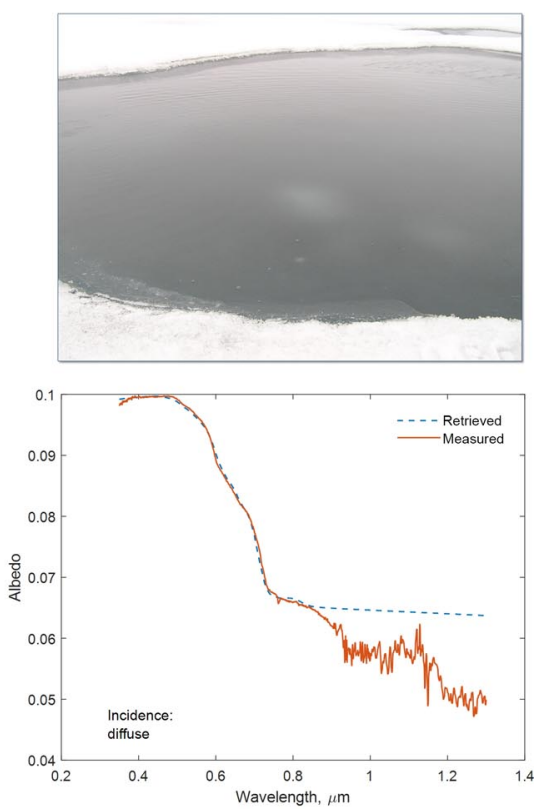

Figure 8. Dark open ponds. Polarstern-2012, Stations 4.

produced quite well. This is because the contribution of the yellow algae spots to a total reflection is proportional to their area, which is not very large. However, their effect can be clearly seen in the spectrum: the measured values are less than the modeled ones in the blue range $(0.3-0.5 \mu \mathrm{m})$ and greater in the yellow-green $(0.5-0.6 \mu \mathrm{m})$.

The above ponds are quite different from one another. They range from dark to very light blue in color, open and frozen over, clear, and contaminated with organic matter. In 
(a)
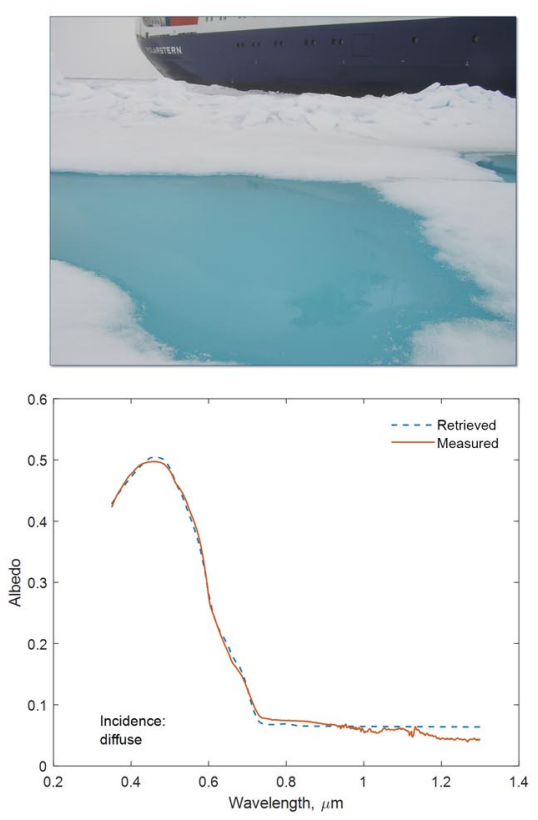

(b)
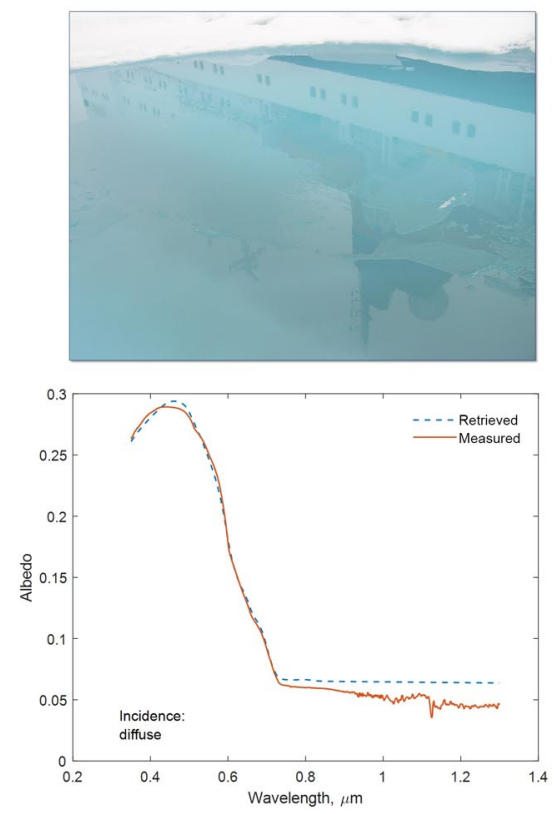

(c)
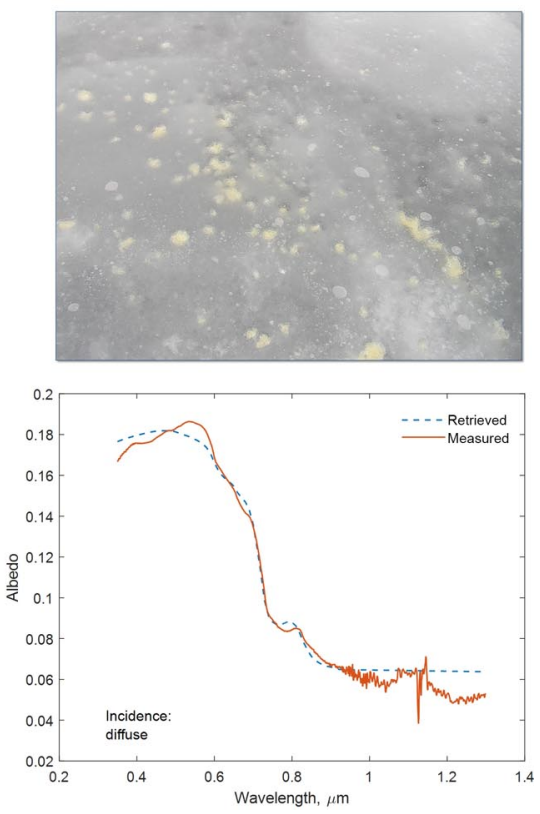

Figure 9. (a) The light-blue pond, (b) a darker part of the blue pond, and (c) the dark pond with yellow algae. Polarstern-2012, Stations 4.

spite of this, the model is able to reproduce the measured spectra in the visible region with high accuracy in all studied cases. The root-mean-square difference (RMSD) between the measured and simulated spectra has the average value of 0.01 for the whole considered spectrum $(0.35-1.3 \mu \mathrm{m})$ and 0.007 for the visible range $(<0.73 \mu \mathrm{m})$.

The retrieved and measured geometrical parameters of the ponds, as well as the RMSD between the measured and simulated spectra, are presented in Table 2 and shown in Fig. 13.

\subsection{Barrow-2008}

Melt pond spectra were observed near Utgiagivik, Alaska, USA (formerly Barrow) in 2008 as part of the SIZONET program, observing pond formation (Polashenski et al., 2012). Observations were collected at sites approximately $1 \mathrm{~km}$ offshore from Niksiuraq in the Chukchi Sea, near $71.366^{\circ} \mathrm{N}$, $156.542^{\circ} \mathrm{W}$ on level, landfast first-year ice. For this work, a total of 27 measured melt pond spectra were used (no photographs were taken). All melt ponds were quite dark and polluted with sediments and their spectra look quite similar. Three of them are presented in Fig. 10. The albedo does not exceed the value of 0.3 in its maximum and shows a discrepancy in the blue range, presumably due to the presence of mineral sediments. Because of this, the RMSD between the measured and simulated spectra for the visible range $(0.01)$ is greater than that for the whole spectrum $(0.009)$. The ice thickness was not measured. The pond depths, measured and retrieved, as well as the RMSD, are shown in Table 2 and Fig. 13.

\subsection{SHEBA-1998}

SHEBA was a year-long drift experiment conducted in the Beaufort Sea from October 1997 to October 1998 (Perovich et al., 1999; Uttal et al., 2002). Extensive measurements of the characteristics of sea ice were made. This included observations of the spatial variability and temporal evolution of the spectral albedo of the ice cover (Perovich et al., 2002).

One pond in this expedition was especially interesting, because its bottom had a region that was much brighter than the surrounding bottom. This region had sharp borders with rectangular corners (see the photo in Fig. 11). This likely was a broken piece of bubbly multi-year ice that was incorporated into the ice cover. This piece of ice had more air bubbles than the darker adjacent ice. This dual pond was observed during the entire period of its formation and development. The most intensive pond formation process was observed from 17 July through 14 August. The spectra were taken every 4 days during this period. The spectra processing results are shown in Figs. 11 and 12.

Figure 11 shows the spectra and the photos of the SHEBA dual pond. For the first five dates $(17,21,25,29$ July, and 2 August) the retrieval is excellent (for the visible range RMSD $=0.0038$ for 17 July and has a maximal value of 0.0061 for 29 July; see Table 2) and for the last three (6, 10,14 August) the retrieval is a little bit worse, but still quite good (for the visible range RMSD $=0.0085$ for 6 and $10 \mathrm{Au}-$ gust). The reason for this difference is not obvious and we may assume that some contaminant got into the pond those 
Table 2. Measure and retrieved pond parameters derived from the spectral range 0.35 to $1.3 \mu \mathrm{m}$ (total). RMSD values between measured and modeled spectra are given for the complete spectral range and the visible part $(\lambda<0.73 \mu \mathrm{m})$.

\begin{tabular}{|c|c|c|c|c|c|c|c|c|}
\hline \multirow[t]{2}{*}{ Figure } & \multirow[t]{2}{*}{ Pond codename } & \multicolumn{2}{|c|}{ Ice thickness $(\mathrm{cm})$, } & \multicolumn{2}{|c|}{ Water depth $(\mathrm{cm})$, } & \multirow{2}{*}{$\begin{array}{c}\sigma_{\mathrm{t}}\left(\mathrm{m}^{-1}\right) \\
\text { retrieved }\end{array}$} & \multicolumn{2}{|c|}{$\mathrm{RMSD} \times 10^{3}$} \\
\hline & & retrieved & measured & retrieved & measured & & (total) & (visible) \\
\hline \multirow{3}{*}{6} & 1008_P2/Polarstern Station 1 & 276 & 230 & 12 & 21 & 2.1 & 13 & 10 \\
\hline & 1008_P3/Polarstern Station 1 & 130 & 225 & 12 & 14 & 5.9 & 22 & 15 \\
\hline & 210812purbp1e00000/Polarstern Station 3 & 163 & 182 & 6 & 11 & 2.2 & 15 & 14 \\
\hline \multirow[t]{3}{*}{7} & 110812ROVtransect23e24p00000/Polarstern Station 1 & 182 & - & 29 & - & 1.2 & 16 & 10 \\
\hline & 210812purbp3e00000 (2208_P3)/Polarstern Station 3 & 212 & 143 & 24 & 30 & 0.91 & 12 & 7.2 \\
\hline & 210812purwhitep4e00000 (2208_P4)/Polarstern Station 3 & 89 & 132 & 0 & 20 & 2.8 & 15 & 13 \\
\hline \multirow[t]{3}{*}{8} & 260812Larm2pond1e00000/Polarstern Station 4 & 19 & - & 95 & 30 & 0.48 & 8.6 & 0.52 \\
\hline & 260812Larm2pond2e00000/Polarstern Station 4 & 33 & - & 59 & 30 & 0.71 & 8.1 & 0.71 \\
\hline & 260812purdpw3e00000 (2608_P3)/Polarstern Station 4 & 63 & 49 & 38 & 30 & 0.16 & 6.6 & 0.40 \\
\hline \multirow[t]{3}{*}{9} & 260812purbp1e00000 (2608_P1)/Polarstern Station 4 & 164 & 256 & 61 & 36 & 1.6 & 9.7 & 6.0 \\
\hline & 260812purbp2de00000/Polarstern Station 4 & 170 & - & 63 & 50 & 0.53 & 11 & 4.0 \\
\hline & 210812puralg5e00000 (2208_P5)/Polarstern Station 4 & 15 & 33 & 22 & 20 & 2.4 & 6.6 & 4.6 \\
\hline \multirow[t]{3}{*}{10} & Barrow, Blue MP \#7 & 53 & - & 22 & 15 & 1.2 & 9.3 & 12 \\
\hline & Barrow, BubblyBlue MP \#4 & 55 & - & 11 & 6 & 1.6 & 10 & 12 \\
\hline & Barrow, BlueWithBrownSpots \#3 & 52 & - & 17 & 20.5 & 1.0 & 8.3 & 11 \\
\hline \multirow[t]{16}{*}{11} & SHEBA light $17 \mathrm{Jul}$ & 72 & - & 38 & 30 & 4.5 & 3.2 & 3.8 \\
\hline & SHEBA light $21 \mathrm{Jul}$ & 70 & - & 38 & 33 & 3.9 & 3.7 & 4.2 \\
\hline & SHEBA light $25 \mathrm{Jul}$ & 41 & - & 45 & 38 & 7.4 & 4.9 & 5.8 \\
\hline & SHEBA light $29 \mathrm{Jul}$ & 44 & - & 51 & 40 & 6.5 & 6.5 & 6.1 \\
\hline & SHEBA light 2 Aug & 48 & - & 49 & 43 & 5.4 & 4.7 & 5.6 \\
\hline & SHEBA light 6 Aug & 6 & - & 72 & 44 & 47 & 7.4 & 8.5 \\
\hline & SHEBA light 10 Aug & 9 & - & 68 & - & 20 & 7.6 & 8.5 \\
\hline & SHEBA light 14 Aug & 83 & - & 30 & - & 1.6 & 6.4 & 6.9 \\
\hline & SHEBA dark $17 \mathrm{Jul}$ & 107 & - & 41 & 30 & 0.88 & 2.0 & 2.2 \\
\hline & SHEBA dark 21 Jul & 108 & - & 44 & 33 & 0.79 & 2.0 & 2.3 \\
\hline & SHEBA dark 25 Jul & 84 & - & 47 & 38 & 0.97 & 2.1 & 2.4 \\
\hline & SHEBA dark 29 Jul & 68 & - & 67 & 40 & 1.3 & 5.3 & 3.3 \\
\hline & SHEBA dark 2 Aug & 75 & - & 52 & 43 & 1.0 & 2.1 & 2.3 \\
\hline & SHEBA dark 6 Aug & 11 & - & 101 & 44 & 4.2 & 4.1 & 2.5 \\
\hline & SHEBA dark 10 Aug & 14 & - & 100 & - & 1.9 & 3.7 & 1.3 \\
\hline & SHEBA dark 14 Aug & 87 & - & 35 & - & 0.24 & 1.8 & 2.1 \\
\hline
\end{tabular}

(a)

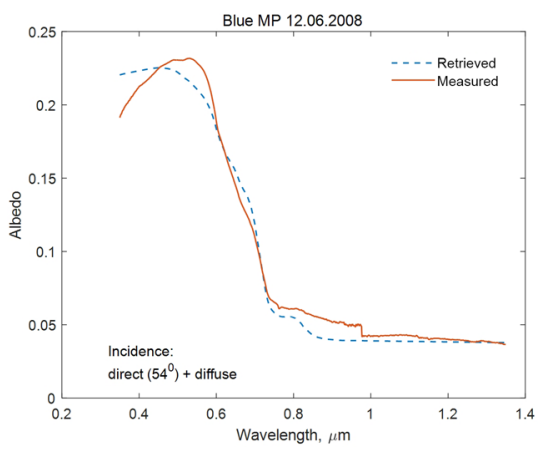

(b)

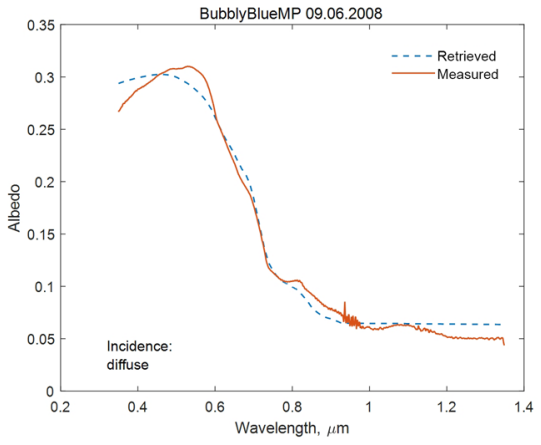

(c)

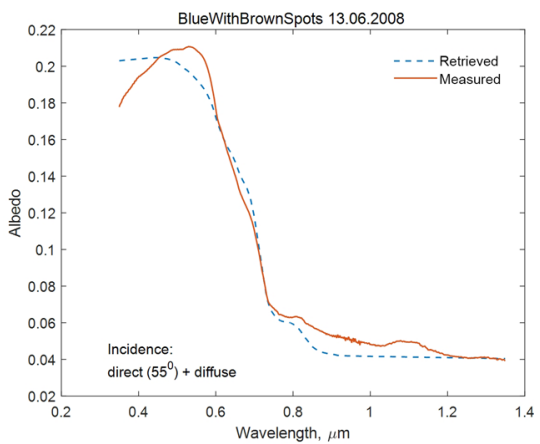

Figure 10. (a) A blue melt pond, (b) a bubbly blue melt pond, and (c) a blue melt pond with brown spots. Barrow-2008.

days. Therefore, the regression analysis relies on the first five measurement dates.

Figure 12 presents the retrieved pond depth and ice thickness (for both parts independently) for these dates. The retrieved pond depth is $7 \mathrm{~cm}$ greater than the average reported pond depth $(37 \mathrm{~cm})$ at the light part of the pond and $13 \mathrm{~cm}$ greater at the dark part. Albedo of the light part (in the visible part of spectrum) is approximately twice greater than that of the dark part. In general, this agrees with the different nature of the pond's physical properties. The retrieved ice thickness 

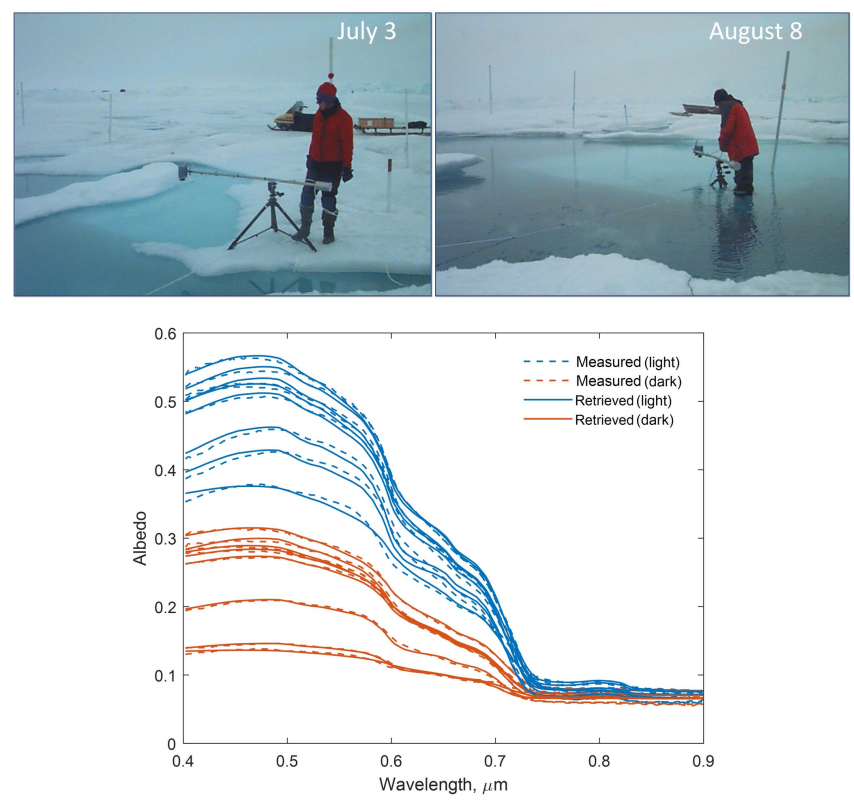

Figure 11. SHEBA-1998 dual pond: photos and spectra (Grenfell et al., 2016), measured (dashed) at the light (blue) and dark (red) parts and simulated (solid). The photographs are taken at the early and late melt season (on 3 July and 8 August, respectively).

in the light part is lower by $34 \mathrm{~cm}$ in average than that of the dark part. The slope of the linear regression for the retrieved ice thickness gives the melt rate of 1.9 and $2.6 \mathrm{~cm} \mathrm{day}^{-1}$ for the light and dark parts, respectively. Taking the average surface and bottom melt for SHEBA ponded ice from 17 July to 14 August gives an estimated surface ice melt of $35 \mathrm{~cm}$ and bottom melt of $28 \mathrm{~cm}$ for a total of $63 \mathrm{~cm}$, which gives a melt rate of $2.25 \mathrm{~cm} \mathrm{day}^{-1}$ (Perovich et al., 2003).

Suppose that the difference between the transport scattering coefficient $\sigma_{\mathrm{t}}$ for the light and dark portion is due to air bubbles only, then the scattering coefficient by air bubbles can be estimated as

$\sigma_{\mathrm{a}}=\frac{\sigma_{\mathrm{t}}^{\text {light }}-\sigma_{\mathrm{t}}^{\text {dark }}}{1-g_{\mathrm{a}}}$.

The retrieved values, averaged for the first five dates, are the following: the transport scattering coefficient for the light part $\sigma_{\mathrm{t}}^{\text {light }}$ is $5.6 \mathrm{~m}^{-1}$, for the dark part $\sigma_{\mathrm{t}}^{\text {dark }}=1.0 \mathrm{~m}^{-1}$ (see Table 2). The slope of the regression line for these five dates is much less than the values scatter. Using the value of 0.86 for $g_{\mathrm{a}}$, we found that the average retrieved scattering coefficient by air bubbles $\sigma_{\mathrm{a}}$ is $33 \mathrm{~m}^{-1}$. In the bubble-saturated ice observed by Gavrilo and Gaitskhoki (1970) the air volume concentration was up to $5 \%$ and the effective bubble radius was $R_{\mathrm{a}}=1.3 \mathrm{~mm}$. If we suppose the same effective radius, the average air volume concentration in the light ice will be $C_{\mathrm{a}}^{\mathrm{V}}=2 / 3 R_{\mathrm{a}} \sigma_{\mathrm{a}}=2.8 \%$, which is quite reasonable for bubbly ice.

\subsection{Verification results}

The retrieved and measured pond parameters (melt water depth, and underlying ice thickness, and transport scattering coefficient), as well as root-mean-square difference (RMSD) between the measured and simulated albedo spectra, are given in Table 2. The RMSD is shown both for the whole spectrum and for the visible range $(\lambda<0.73 \mu \mathrm{m})$. A scatter plot of the retrieved pond parameters is shown in Fig. 13. The maximal error is $55 \%$, the relative RMSD is $37 \%$, and $R^{2}=$ 0.56 . There could be different sources of error. One source could come from the fact that the most important parameter that determines the pond albedo is the transport optical thickness of under-pond ice $\tau_{\mathrm{t}}$ that is a product of the transport scattering coefficient $\sigma_{\mathrm{t}}$ and ice thickness $H: \tau_{\mathrm{t}}=\sigma_{\mathrm{t}} H$. Partially this explains the retrieval error: the sensitivity of the albedo to $\tau_{\mathrm{t}}$ is twice greater than that to $\sigma_{\mathrm{t}}$ and $H$ separately. Second, the under-pond ice might not be flat, especially its lower boundary. In this case the optical retrieval gives some average value, while the in situ measurement gives a random value taken in some particular point. The third source can be the presence of some impurities that affect the absorption spectrum. Additional absorption can affect the retrieval of the scattering coefficient and, consequently, of $H$. In addition, there could be other sources of uncertainties, like finite pond size, presence of snow in the receiver field of view, and clouds in the sky. Considering this, the retrieval of the underlying ice thickness seems reasonable. Let us note the fact that microwave sounding methods completely fail in ice thickness retrieval when ice is covered with water.

The retrieval of the pond depth is more uncertain: its value can differ up to 2 times from the measured one and $\mathrm{RMSD}=65 \%$. This is to be expected, because the pond water depth has much less effect on the pond albedo than the underlying ice thickness. Nevertheless, the correlation for the entire dataset of the measured and retrieved pond depth values is quite high $\left(R^{2}=0.62\right)$ and $70 \%$ of the retrieved values are inside the $50 \%$ error range. The observed scatter in the retrieval results might partly be explained by the specifics of the field measurements of the water depth and ice thickness in the melt pond: ice drillings or water depth measurements are performed at one single point of the melt pond and do not necessarily represent the average ice thickness or water depth values, which can be highly variable. The transport scattering coefficient was not measured in any of the campaigns. We can only say that the retrieved values match the interval $0.1-10 \mathrm{~m}^{-1}$, indicated in Sect. 2.2.3.

Summarizing the verification, we can say that the spectra retrieval in the visible range is good for all cases considered. Some difference is observed in the blue, when colored organic matter or mineral sediments are present in the ice or melt water, and in the IR, where the reflectance is too low and the signal is noisy. 
(a)

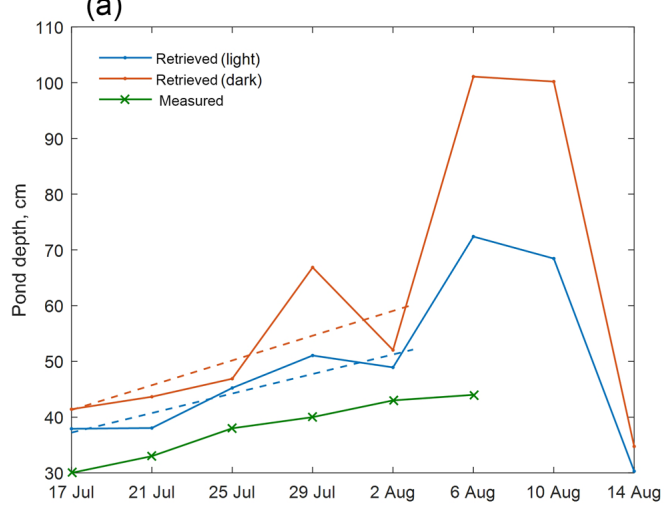

(b)

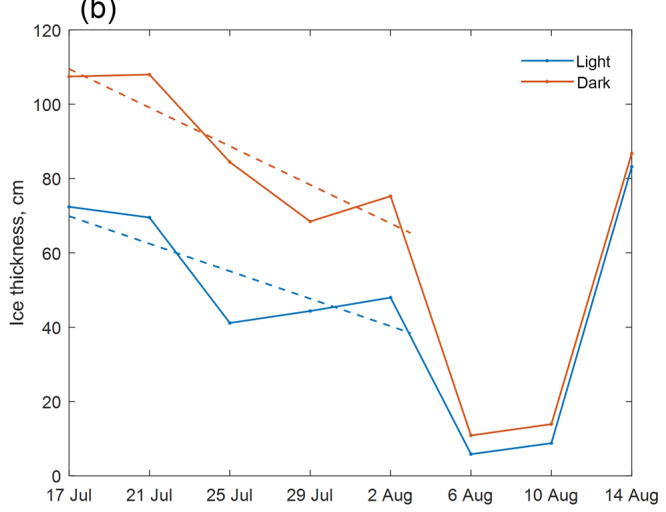

Figure 12. Retrieved pond depth (a) and ice thickness (b) for the two parts of the dual pond shown in Fig. 11. The measured pond depth is shown with crosses. The dashed lines show the linear regression for the first five dates.

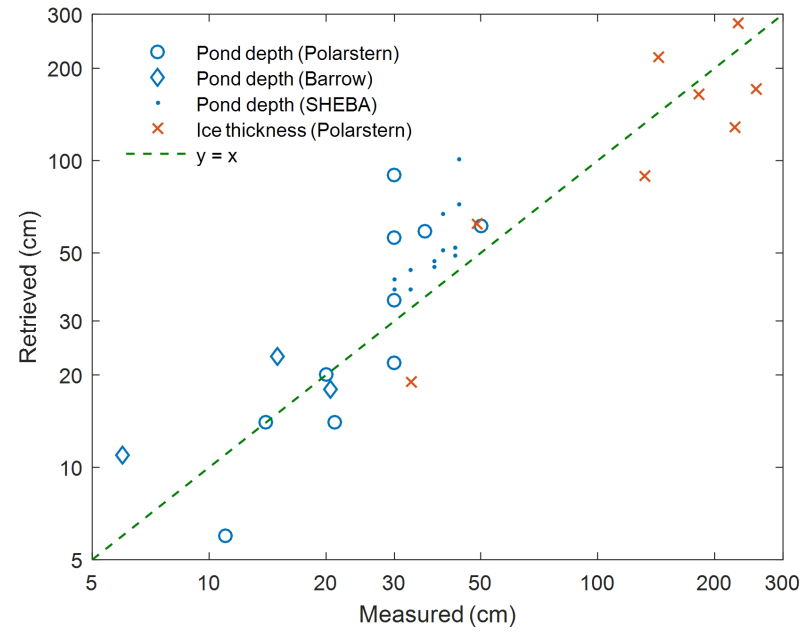

Figure 13. Ice thickness and pond depth, measured at different stations and retrieved. For ice thickness $R^{2}=0.56(N=8)$ and for pond depth $R^{2}=0.62(N=26)$.

\section{Conclusion}

This work presents an optical model of melt ponds on sea ice. The melt pond model described in this work relates the optical properties of a melt pond (spectral albedo and angular reflectance) to its physical characteristics (microphysical ice properties, water depth, sea-ice thickness, sediment amount) at various sky conditions.

We assume a pond to be a plane-parallel layer of melt water on an under-pond ice layer. We paid particular attention to the pond bottom albedo as the main factor that determines the pond reflectance. The albedo of the under-pond ice is calculated within the modified two-stream approximation (Zege et al., 1991), which relates the layer albedo to its thickness and to the transport scattering coefficient of a medium. The analysis of the spectral behavior of the inherent optical properties of sea ice, using the WKB approximation approach to light scattering by non-spherical particles (brine inclusions) and Mie solution for spherical particles (air bubbles), has shown that the average cosine of the scattering phase function, and therefore the transport scattering coefficient of sea ice, is spectrally neutral. Hence, the pond can be characterized by only three independent parameters that determine its reflectance through the visible and near-IR spectral range: the pond depth, the under-pond ice thickness, and the ice transport scattering coefficient.

The model developed proposes the simple analytical formulas to calculate the main reflective characteristics of a melt pond: the bidirectional reflectance factor and the black- and white-sky albedo. The model is simple in its implementation, because it is entirely based on analytical formulas. The derivation of the analytical formulas becomes possible due to the assumption of the Lambert reflection by the pond bottom. Although this commonly used assumption has no reliable experimental basis, the model verification with a wide set of field measurements (SHEBA-1998, Barrow-2008, and Polarstern-2012) confirms that this assumption is reasonable, at least concerning the spectral albedo. Its validity for the pond bidirectional reflectance requires further investigations.

Additional attention is paid to correctly accounting for the illumination conditions during the field measurements. It is shown that multiple reflections of light between the atmosphere and surrounding background can be neglected, so the a priori knowledge of the background (surrounding ice) albedo is not necessary. However, the sky conditions (overcast or clear, presence of cirrus or aerosol load) should be specified to interpret the pond albedo as the white-, black, or blue-sky ones. In the last case it is highly desirable to know the spectrally resolved atmospheric optical thickness during the measurements. Unfortunately, such information is rarely available for field measurements of the sea-ice reflective properties.

The model can be used to study the distribution of melt pond physical properties and temporal evolution of the smallscale sea-ice morphology during summer melt. The melt 
pond model is necessary to retrieve the melt pond fraction from optical satellite data of moderate resolution (with pixel size starting from hundreds of meters), where melt ponds become subpixel. In turn, the amount of melt ponds on Arctic sea ice determines the sea-ice reflectance and transmittance and thus allows estimating the energy balance above, within, and under sea ice and its response to climate change. The temporal evolution of melt ponds consists of melt stages, which are specific to sea-ice type (landfast ice, first-, second-, or multi-year ice). The spring melt pond fraction predicts the autumn Arctic sea-ice extent. Therefore, the melt pond fraction dataset obtained from satellite data is required to derive the sea-ice extent and type during summer melt.

The model presented has been already used in an algorithm for sea-ice albedo and melt pond fraction retrieval from MERIS satellite data (Zege et al., 2015; Istomina et al., 2015a, b). The model provides accurate description of the melt pond reflective properties: not only pond albedo but also pond bidirectional reflectance, which is of great importance for processing satellite data. Moreover, the approach presented can be easily extended to describe the light transmittance through sea ice, which is also important for the radiative budget of the Arctic Ocean. The model presented is able to reproduce a variety of melt pond types observed in the field. It can be applied to the problems of physics of sea ice and to monitoring the melt of the Arctic and Antarctic sea-ice cover. Also, it makes it possible to improve the parameterization of the underlying surface in various atmospheric remote sensing retrievals over the Arctic summer sea ice (clouds, aerosols, trace gases) and potentially re-evaluate the climatic feedbacks and radiative budget of the Arctic region at a new accuracy level.

Data availability. The field data from the R/V Polarstern cruise ARK XXVII/3 are available at the PANGAEA data repository (Istomina et al., 2016, 2017).

The field data from the Barrow-2008 expedition are available at the Arctic Data Center: spectral albedos - Polashenski et al. (2016a); line photos - Polashenski et al. (2016b).

The field data from the SHEBA-1998 expedition are available at https://arcticdata.io/catalog/\#view/urn:uuid: f6989fd6-27e4-4f0f-b322-5e6ed332cf35.

Competing interests. The authors declare that they have no conflict of interest.

Acknowledgements. The work was supported by the Institutional Strategy of the University of Bremen, funded by the German Excellence Initiative, and by the TR 172 "ArctiC Amplification: Climate Relevant Atmospheric and SurfaCe Processes, and Feedback Mechanisms (AC)3", funded by the German Research Foundation (DFG).
The authors are grateful to the scientific party of the ARK XVII/3 cruise for making the spectral albedo measurements possible. Special thanks are expressed to Marcel Nicolaus for organizing the logistics and to the Sea Ice Physics group on board for assisting with the measurements.

The article processing charges for this open-access publication were covered by the University of Bremen.

Edited by: Jean-Louis Tison

Reviewed by: two anonymous referees

\section{References}

Barry, R. G.: The parameterization of surface albedo for sea ice and its snow cover, Prog. Phys. Geog., 20, 63-79, 1996.

Boetius, A. and ARK-XXVII/3 Shipboard Scientific Party: List of sea ice measurements during Polarstern cruise ARKXXVII/3 (IceArc), Alfred Wegener Institute, Helmholtz Center for Polar and Marine Research, Bremerhaven, https://doi.org/10.1594/PANGAEA.792734 (last access: 24 May 2018), 2012.

Buiteveld, H., Hakvoort, J. H., Donze, M.: The optical properties of pure water, in: Ocean Optics XII, edited by: Jaffe, J. J., Proc. SPIE, 2258, 174-183, 1994

Chandrasekhar, S.: Radiative transfer, New York, Dover, 1960.

Comiso, J. C.: Large decadal decline of the Arctic multiyear ice cover, J. Climate, 25, 1176-1193, https://doi.org/10.1175/JCLID-11-00113.1, 2012.

Curry, J. A., Schramm, J. L., and Ebert, E. E.: Sea-ice albedo climate feedback mechanism, J. Climate, 8, 240-247, 1995.

Daimon, M. and Masumura, A.: Measurement of the refractive index of distilled water from the near-infrared region to the ultraviolet region, Appl. Optics, 46, 3811-3820, 2007.

Davison, B.: Neutron transport theory, Oxford, Clarendon Press, 1958.

Dethloff, K., Rinke, A., Benkel, A., Køltzow, M., Sokolova, E., Kumar Saha, S., Handorf, D., Dorn, W., Rockel, B., Storch, H. von, Haugen, J. E., Røed, L. P., Roeckner, E., Christensen, J. H., and Stendel, M.: A dynamical link between the Arctic and the global climate system, Geophys. Res. Lett., 33, L03703, https://doi.org/10.1029/2005GL025245, 2006.

Eicken, H., Grenfell, T. C., Perovich, D. K., Richter-Menge, J. A., and Frey, K.: Hydraulic controls of summer Arctic pack ice albedo, J. Geophys. Res., 109, C08007, https://doi.org/10.1029/2003JC001989, 2004.

Flocco, D., Feltham, D. L., and Turner, A. K.: Incorporation of a physically based melt pond scheme into the sea ice component of a climate model, J. Geophys. Res., 115, C08012, https://doi.org/10.1029/2009JC005568, 2010.

Flocco, D., Schroeder, D., Feltham, D. L., and Hunke, E. C.: Impact of melt ponds on Arctic sea ice simulations from 1990 to 2007, J. Geophys. Res. 117, C09032, https://doi.org/10.1029/2012JC008195, 2012.

Frisvad, J. R.: Empirical formula for the refractive index of freezing brine, Appl. Optics, 48, 2149-2153, https://doi.org/10.1364/AO.48.002149, 2009. 
Gavrilo, V. P. and Gaitskhoki, B. Y.: The statistics of air inclusions in ice, in: The Physics of Ice, edited by: Bogorodskii, V. V., translated from Russian, Isr. Program for Sci. Transl., Jerusalem, 125$128,1970$.

Grenfell, T. C., Light, B., and Perovich, D.: Spectral Albedo [Grenfell, T. and Light, B.], Arctic Data Center, https://doi.org/10.5065/D6765CQ1 (last access: 31 May 2018), version: urn:uuid:f6989fd6-27e4-4f0f-b322-5e6ed332cf35, 2016.

Hale, G. M. and Querry, M. R.: Optical constants of water in the 200-nm to 200- $\mu \mathrm{m}$ wavelength region, Appl. Optics, 12, 555563, https://doi.org/10.1364/AO.12.000555, 1973.

Herzfeld, U. C., Maslanik, J. A., and Sturm, M.: Geostatistical Characterization of Snow-Depth Structures on Sea Ice Near Point Barrow, Alaska - A Contribution to the AMSR-Ice03 Field Validation Campaign, IEEE T. Geosci. Remote, 44, 3038-3056, 2006.

Hunke, E. C., Hebert, D. A., and Lecomte, O.: Level-ice melt ponds in the Los Alamos sea ice model, CICE, Ocean Model., 71, 2642, 2013.

Istomina, L., Heygster, G., Huntemann, M., Schwarz, P., Birnbaum, G., Scharien, R., Polashenski, C., Perovich, D., Zege, E., Malinka, A., Prikhach, A., and Katsev, I.: Melt pond fraction and spectral sea ice albedo retrieval from MERIS data - Part 1: Validation against in situ, aerial, and ship cruise data, The Cryosphere, 9, 1551-1566, https://doi.org/10.5194/tc9-1551-2015, 2015a.

Istomina, L., Heygster, G., Huntemann, M., Marks, H., Melsheimer, C., Zege, E., Malinka, A., Prikhach, A., and Katsev, I.: Melt pond fraction and spectral sea ice albedo retrieval from MERIS data Part 2: Case studies and trends of sea ice albedo and melt ponds in the Arctic for years 2002-2011, The Cryosphere, 9, 15671578, https://doi.org/10.5194/tc-9-1567-2015, 2015 b.

Istomina, L., Nicolaus, M., and Perovich, D. K.: Surface spectral albedo complementary to ROV transmittance measurements at 6 ice stations during POLARSTERN cruise ARK XXVII/3 (IceArc) in 2012, PANGAEA, https://doi.org/10.1594/PANGAEA.867292 (last access: 24 May 2018), 2016.

Istomina, L., Nicolaus, M., and Perovich, D. K.: Spectral albedo, water depth and ice thickness within melt ponds measured during POLARSTERN cruise ARK-XXVII/3 (IceArc) in 2012, PANGAEA, https://doi.org/10.1594/PANGAEA.876210 (last access: 24 May 2018), 2017.

Kedenburg, S., Vieweg, M., Gissibl, T., and Giessen, H.: Linear refractive index and absorption measurements of nonlinear optical liquids in the visible and near-infrared spectral region, Opt. Mater. Express, 2, 1588-1611, 2012.

Kopelevich, O. V.: Low-parametric model of seawater optical properties, in: Ocean Optics I: Physical Ocean Optics, edited by: Monin, A. S., Moscow, Nauka, 208-234, 1983.

Langleben, M. P.: Albedo of melting sea ice in the southern Beaufort Sea, J. Glaciol., 10, 101-104, 1971.

Light, B.: Theoretical and observational techniques for estimating light scattering in first-year Arctic sea ice, in: Light Scattering Reviews 5: Single Light Scattering and Radiative Transfer, edited by: Kokhanovsky, A., Berlin, Springer, 331-391, 2010.
Light, B., Eicken, H., Maykut, G. A., and Grenfell, T. C.: The effect of included particulates on the spectral albedo of sea ice, J. Geophys. Res., 103, 27739-27752, 1998.

Light, B., Maykut, G. A., and Grenfell, T. C.: Effects of temperature on the microstructure of first-year Arctic sea ice, J. Geophys. Res., 108, 3051, https://doi.org/10.1029/2001JC000887, 2003.

Lüpkes, C., Gryanik, V. M., Rösel, A., Birnbaum, G., and Kaleschke, L.: Effect of sea ice morphology during Arctic summer on atmospheric drag coefficients used in climate models, Geophys. Res. Lett., 40, 446-451, https://doi.org/10.1002/grl.50081, 2013.

Malinka, A.: Analytical expressions for characteristics of light scattering by arbitrarily shaped particles in the WKB approximation, J. Opt. Soc. Am. A, 32, 1344-1351, https://doi.org/10.1364/JOSAA.32.001344, 2015.

Malinka, A., Zege, E., Heygster, G., and Istomina, L.: Reflective properties of white sea ice and snow, The Cryosphere, 10, 25412557, https://doi.org/10.5194/tc-10-2541-2016, 2016a.

Malinka, A., Zege, E., Katsev, I., Prikhach, A., and Istomina, L.: Accounting for atmospheric effects in the interpretation of satellite and ground-based optical measurements, J. Appl. Spectrosc., 83, 741-749, https://doi.org/10.1007/s10812-016-0357-3, 2016b.

Makshtas, A. P. and Podgorny, I. A.: Calculation of melt pond albedos on arctic sea ice, Polar Res., 15, 43-52, 1996.

Markus, T., Stroeve, J. C., and Miller, J.: Recent changes in Arctic sea ice melt onset, freezeup, and melt season length, J. Geophys. Res., 114, C12024, https://doi.org/10.1029/2009JC005436, 2009.

Maslanik, J., Fowler, C., Stroeve, J., Drobot, S., Zwally, J., Yi, D., and Emery, W.: A younger, thinner Arctic ice cover: Increased potential for rapid, extensive sea-ice loss, Geophys. Res. Lett., 34, L24501, https://doi.org/10.1029/2007GL032043, 2007.

Maslanik, J., Stroeve, J., Fowler, C., and Emery, W.: Distribution and trends in Arctic sea ice age through spring 2011, Geophys. Res. Lett., 38, L13502, https://doi.org/10.1029/2011GL047735, 2011.

Maykut, G. A. and Light, B.: Refractive-index measurements in freezing sea-ice and sodium chloride brines, Appl. Optics, 34, 950-961, 1995.

Maykut, G. A., Grenfell, T. C., and Weeks, W. F.: On estimating the spatial and temporal variations in the properties of ice in the polar oceans, J. Marine Syst., 3, 41-72, 1992.

Mobley, C. D., Cota, G. F., Grenfell, T. C., Maffione, R. A., Pegau, W. S., and Perovich, D. K.: Modeling Light Propagation in Sea Ice, IEEE T. Geosci. Remote, 36, 1743-1749, 1998.

Morassutti, M. F. and Ledrew, E. F.: Albedo and depth of melt ponds on sea-ice, Int. J. Climatol., 16, 817-838, 1996.

Nicolaus, M., Gerland, S., Hudson, S. R., Hanson, S., Haapala, J., and Perovich, D. K.: Seasonality of spectral albedo and transmittance as observed in the Arctic Transpolar Drift in 2007, J. Geophys. Res., 115, C11011, https://doi.org/10.1029/2009JC006074, 2010.

Perovich, D. K.: Light reflection from sea ice during the onset of melt, J. Geophys. Res., 99, 3351-3359, 1994.

Perovich, D. K.: The optical properties of sea ice, US Army Cold Regions Research and Engineering Laboratory (CRREL) Report 96-1, Hanover, NH, USA, available at: www.dtic.mil/cgi-bin/ GetTRDoc?AD=ADA310586 (last access: 24 March 2017), 1996. 
Perovich, D. K., Andreas, E. L., Curry, J. A., Eiken, H., Fairall, C. W., Grenfell, T. C., Guest, P. S., Intrieri, J., Kadko, D., Lindsay, R. W., McPhee, M. G., Morison, J., Moritz, R. E., Paulson, C. A., Pegau, W. S., Persson, P. O. G., Pinkel, R.. Richter-Menge, J. A., Stanton, T., Stern, H., Sturm, M., Tucker III, W. B., and Uttal, T.: Year on ice gives climate insights, EOS T. Am. Geophys. Un., 80, 485-486, https://doi.org/10.1029/EO080i041p00481-01, 1999.

Perovich, D. K., Grenfell, T. C., Light, B., and Hobbs, P. V.: Seasonal evolution of the albedo of multiyear Arctic sea ice, J. Geophys. Res., 107, 8044, https://doi.org/10.1029/2000JC000438, 2002.

Perovich, D. K., Grenfell, T. C., Richter-Menge, J. A., Light, B., Tucker III, W. B., and Eicken, H.: Thin and thinner: ice mass balance measurements during SHEBA, J. Geophys. Res., 108, 8050, https://doi.org/10.1029/2001JC001079, 2003.

Perovich, D. K., Richter-Menge, J. A., Jones, K. F., and Light, B.: Sunlight, water and ice: extreme Arctic sea ice melt during the summer of 2007, Geophys. Res. Lett., 35, L11501, https://doi.org/10.1029/2008GL034007, 2008.

Perovich, D. K., Grenfell, T. C., Light, B., Elder, B. C., Harbeck, J., Polashenski, C., Tucker III, W. B., and Stelmach, C.: Transpolar observations of the morphological properties of Arctic sea ice, J. Geophys. Res., 114, C00A04, https://doi.org/10.1029/2008JC004892, 2009.

Pirazzini, R.: Factors Controlling the Surface Energy Budget over Snow and Ice, Academic Dissertation in meteorology, Finnish Meteorological Institute, Helsinki, 2008.

Pistone, K., Eisenmann, I., and Ramanathan, V.: Observational determination of albedo decrease caused by vanishing Arctic sea ice, P. Natl. Acad. Sci. USA, 111, 3322-3326, https://doi.org/10.1073/pnas.1318201111, 2014.

Polashenski, C., Perovich, D., and Courville, Z.: The mechanisms of sea ice melt pond formation and evolution, J. Geophys. Res., 117, C01001, https://doi.org/10.1029/2011JC007231, 2012.

Polashenski, C., Claffey, K., Courville, Z., Petrich, C., and Perovich, D.: Sea Ice Melt Ponds: Spectral Albedo, Arctic Data Center, https://doi.org/10.5065/D6NZ85TB (last access: May 2018), 2016a.

Polashenski, C., Claffey, K., Courville, Z., Petrich, C., and Perovich, D.: Sea Ice Melt Ponds: Individual Line Photos, urn:node:ARCTIC, https://doi.org/10.5065/D6J1019P (last access: May 2018), 2016b.

Quan, X. and Fry, E. S.: Empirical equation for the index of refraction of seawater, Appl. Optics, 34, 3477-3480, 1995.

Rösel, A., Kaleschke, L., and Birnbaum, G.: Melt ponds on Arctic sea ice determined from MODIS satellite data using an artificial neural network, The Cryosphere, 6, 431-446, https://doi.org/10.5194/tc-6-431-2012, 2012.

Sankelo, P., Haapala, J., Heiler, I., and Rinne, E.: Melt pond formation and temporal evolution at the drifting station Tara during summer 2007, Polar Res., 29, 311-321, https://doi.org/10.1111/j.1751-8369.2010.00161.x, 2010.
Schröder, D., Feltham, D. L., Flocco, D., and Tsamados, M.: September Arctic sea-ice minimum predicted by spring melt-pond fraction, Nat. Clim. Change, 4, 353-357, https://doi.org/10.1038/nclimate2203, 2014.

Segelstein, D.: The Complex Refractive Index of Water, MS thesis, University of Missouri, Kansas City, available at: https:// mospace.umsystem.edu/xmlui/handle/10355/11599 (last access: 12 December 2016), 1981.

Serreze, M. C., Walsh, J. E., Chapin III, F. S., Osterkamp, T., Dyurgerov, M., Romanovsky, V., Oechel, W. C., Morison, J., Zhang, T., and Barry, R. G.: Observational evidence of recent change in the northern highlatitude environment, Clim. Change, 46, 159-207, 2000.

Tomasi, C., Vitale, V., Lupi, A., Di Carmine, C., Campanelli, M., Herber, A., Treffeisen, R., Stone, R. S., Andrews, E., Sharma, S., Radionov, V., von Hoyningen-Huene, W., Stebel, K., Hansen, G. H., Myhre, C. L., Wehrli, C., Aaltonen, V., Lihavainen, H., Virkkula, A., Hillamo, R., Ström, J., Toledano, C., Cachorro, V. E., Ortiz, P., de Frutos, A. M., Blindheim, S., Frioud, M., Gausa, M., Zielinski, T., Petelski, T., and Yamanouchi, T.: Aerosols in polar regions: A historical overview based on optical depth and in situ observations, J. Geophys. Res., 112, D16205, https://doi.org/10.1029/2007JD008432, 2007.

Tschudi, M. A., Maslanik, J. A., and Perovich, D. K.: Derivation of melt pond coverage on Arctic sea ice using MODIS observations, Remote Sens. Environ., 112, 2605-2614, 2008.

Uttal, T., Curry, J. A., McPhee, M. G., Perovich, D. K., Moritz, R. E., Maslanik, J. A., Guest, P. S., Stern, H. L., Moore, J. A., Turenne, R., Heiberg, A., Serreze, M. C., Wylie, D. P., Persson, O. G., Paulson, C. A., Halle, C., Morison, J. H., Wheeler, P. A., Makshtas, A., Welch, H., Shupe, M. D., Intrieri, J. M., Stamnes, K., Lindsey, R. W., Pinkel, R., Pegau, W. S., Stanton, T. P., and Grenfeld, T. C.: Surface Heat Budget of the Arctic Ocean, B. Am. Meteorol. Soc., 83, 255-275, https://doi.org/10.1175/15200477(2002)083<0255:SHBOTA> 2.3.CO;2, 2002.

Warren, S. G. and Brandt, R. E.: Optical constants of ice from the ultraviolet to the microwave: A revised compilation, J. Geophys. Res., 113, D14220, https://doi.org/10.1029/2007JD009744, 2008.

Wiscombe, W. J. and Warren, S. G.: A model for the spectral albedo of snow, I. Pure snow, J. Atmos. Sci., 37, 2712-2733, 1980.

Zege, E., Malinka, A., Katsev, I., Prikhach, A., Heygster, G., Istomina, L., Birnbaum, G., and Schwarz, P.: Algorithm to retrieve the melt pond fraction and the spectral albedo of Arctic summer ice from satellite optical data, Remote Sens. Environ., 163, 153-164, https://doi.org/10.1016/j.rse.2015.03.012, 2015.

Zege, E. P., Ivanov, A. P., and Katsev, I. L.: Image transfer through a scattering medium, Heidelberg, Springer-Verlag, 1991. 